\title{
Determinants of resistance to VEGF-TKI and immune checkpoint inhibitors in metastatic renal cell carcinoma
}

Revati Sharma ${ }^{1,2}$, Elif Kadife ${ }^{1}$, Mark Myers ${ }^{2}$, George Kannourakis ${ }^{1,2}$, Prashanth Prithviraj ${ }^{1+}$ and Nuzhat Ahmed ${ }^{1,2,3,4^{*+}}$

\begin{abstract}
Vascular endothelial growth factor tyrosine kinase inhibitors (VEGF-TKIs) have been the mainstay of treatment for patients with advanced renal cell carcinoma (RCC). Despite its early promising results in decreasing or delaying the progression of RCC in patients, VEGF-TKls have provided modest benefits in terms of disease-free progression, as 70\% of the patients who initially respond to the treatment later develop drug resistance, with $30 \%$ of the patients innately resistant to VEGF-TKIs. In the past decade, several molecular and genetic mechanisms of VEGF-TKI resistance have been reported. One of the mechanisms of VEGF-TKIs is inhibition of the classical angiogenesis pathway. However, recent studies have shown the restoration of an alternative angiogenesis pathway in modulating resistance. Further, in the last 5 years, immune checkpoint inhibitors (ICls) have revolutionized RCC treatment. Although some patients exhibit potent responses, a non-negligible number of patients are innately resistant or develop resistance within a few months to ICl therapy. Hence, an understanding of the mechanisms of VEGF-TKI and ICI resistance will help in formulating useful knowledge about developing effective treatment strategies for patients with advanced RCC. In this article, we review recent findings on the emerging understanding of RCC pathology, VEGF-TKI and ICI resistance mechanisms, and potential avenues to overcome these resistance mechanisms through rationally designed combination therapies.
\end{abstract}

Keywords: Clear cell renal carcinoma, Metastatic renal cell carcinoma, Vascular endothelial growth factor, tyrosine kinase inhibitor, Sunitinib, Hypoxia, Epithelial mesenchymal transition

\section{Background}

Kidney cancer is the ninth most common cancer in men and fourteenth in women. In 2018, there were 400,000 new cases around the globe [1]. Renal cell carcinoma (RCC) makes up to $95 \%$ of renal malignancies [2]. RCC arises from the renal tubular epithelium, which lines the proximal convoluted tubules and constitutes of very small tubes in the kidney responsible for transporting urine. According to the 2012 consensus conference of the International Society of Urological Pathology (ISUP),

\footnotetext{
*Correspondence: nuzhata@unimelb.edu.au; nuzhat@fecri.org.au

${ }^{+}$Prashanth Prithviraj and Nuzhat Ahmed contributed equally to this work.

${ }^{1}$ Fiona Elsey Cancer Research Institute, Ballarat, Victoria 3350, Australia

${ }^{2}$ Federation University Australia, Ballarat, Victoria 3350, Australia

Full list of author information is available at the end of the article
}

there are 15 subtypes of RCC with diverse genetic and epigenetic characteristics, of which clear cell RCC (ccRCC) occurs most frequently (80\%). Papillary RCC (10-15\%) and chromophobe RCC (5\%) are the common remaining histologic subtypes [3]. Around $50 \%$ of RCC is detected incidentally with one-quarter of the patients diagnosed with metastatic disease and another 30\% that relapse and develop metastatic RCC (mRCC) after undergoing curative nephrectomy. These patient groups are considered at high risk of death due to RCC [4]. The morbidity and mortality rates of advanced RCC are high, with a five-year survival rate of only $18 \%$ [5]. All subtypes of RCC are innately resistant to traditional cancer treatments, such as chemotherapy and radiotherapy. 


\section{RCC histology}

The gross morphological appearance of RCC varies between tumour types. In general, most RCC presents with areas of extensive network of blood vessels with cysts containing watery fluid and areas of cancer cells (Fig. 1). The ccRCC stores glycogen and lipids and the cells contain clear cytoplasm and a central nucleus encompassed by an intact plasma membrane. Due to the extensive vascular network, the stroma in most cancer cells shrinks, the surrounding parenchyma is constricted, and the tumour is confined to capsular structures [6]. Nonclear cell RCC is a group of diseases, each with different histologic subtypes and different clinical course and outcomes. The most common are papillary RCC (pRCC) and chromophobe RCC (chRCC). pRCC, which show a papillary pattern, although tubular structures or solid growth patterns can be seen but are rare. In the case of chRCC, the growth pattern is often solid, comprised of sheets of tumour cells containing long linear parallel vessels in contrast to the thin delicate network of vessels of ccRCC [7].

\section{Genetic alterations in RCC}

Genetic alterations are common in RCC and usually involve loss of tumour suppressor genes by deletion or functional inactivation or by hypermethylation of the gene promoter [8]. Classically, 70\% of ccRCC carry a mutation in the von Hippel-Lindau (VHL) gene, which encodes VHL protein (pVHL) [9, 10]. pVHL exerts its tumour suppressing function by binding to and mediating the degradation of hypoxia-inducible factor (HIF). The development of RCC in most cases occurs by deletion or mutation on both alleles of $V H L$ [9]. The loss or mutation in $V H L$ results in the inactivation of pVHL, leading to the activation and accrual of HIF proteins (HIF- $1 \alpha$, HIF- $\alpha$ and HIF- $3 \alpha$ ) and transcription of downstream target genes $[4,10]$. The activation of HIF target genes is fundamental to the pathogenesis of RCC due to their role in promoting angiogenesis, tumour cell survival, proliferation, disease progression, glucose metabolism, and metastatic spread. HIF is also composed of a $\beta$ subunit (HIF-1 $\beta$ ). HIF-1 $\beta$ is stable and constitutively expressed, whereas HIF $\alpha$ subunits are highly unstable and are controlled by cellular oxygen levels. Under normoxic conditions, prolyl 2-oxoglutarate-dependent $\mathrm{Fe}^{2+}$ dioxygenases PHD1, PHD2, and PHD3 hydroxylate the two conserved proline residues in HIF $\alpha$ subunits. The hydroxylated proline residues are targets of VHL/E3 ubiquitin ligase complex, resulting in the protease-mediated degradation of HIF $\alpha$. However, during hypoxia, PHDs cannot hydroxylate $\mathrm{HIF} \alpha$, leading to their stabilisation and activation of downstream target genes, which mostly regulate the expression of angiogenic and tissue remodelling proteins [11]. Stabilised HIF-1 $\alpha$ also enhances the expression of glycolytic enzymes lactate dehydrogenase (LDH), pyruvate dehydrogenase kinase (PDK), and other glycolysis-related genes, such as glucose transporter-1 (GLUT-1) and hexokinase (HK), which consequently increase glucose uptake and glycolysis, thus reducing the carbon flux through the tricarboxylic acid (TCA) cycle and oxidative phosphorylation in RCC [12, 13]. Enhanced expression of HIF-1 $\alpha$ target genes GLUT1, HK, LDH, PDK1 and PKM2 in ccRCC compared to matching adjacent normal kidney tissues are represented in Fig. 2.

Hence, HIF- $1 \alpha$ is a vital metabolic checkpoint for RCC and is essential for the development of RCC in vivo. Recent studies have shown that inactivation of both HIF- $1 \alpha$ and HIF- $2 \alpha$ hampers the development of ccRCC in mouse models, suggesting that both HIF $\alpha$ genes may be crucial for ccRCC initiation and progression [15]. However, $30-40 \%$ of clinically diagnosed ccRCC lack the expression of HIF-1 $\alpha$, suggesting that HIF- $1 \alpha$ may act as a tumour suppressor gene in those scenarios where its expression may be mandatory for initial development

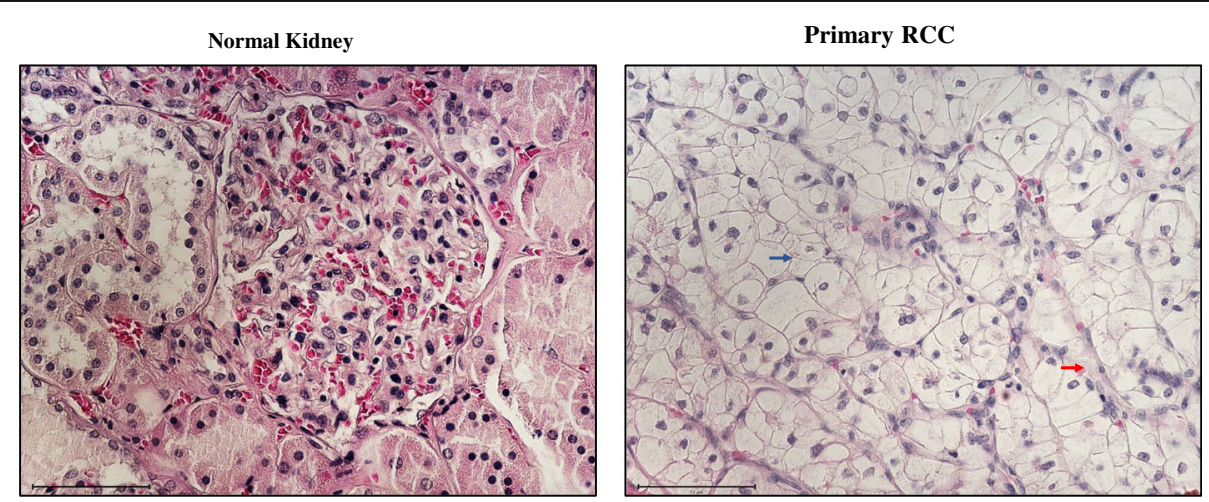

Fig. 1 Haematoxylin and eosin ( $H$ and E) stained paraffin embedded ccRCC section and its corresponding normal kidney tissue. Histopathological slides showing $\mathrm{H}$ and $\mathrm{E}$ images of normal kidney with well-defined glomerulus and tubules, and conventional ccRCC with typical histological appearance of epithelial nests of large uniform cells with clear cytoplasm and distinct cell membrane (blue arrow). Delicate branches of blood vessels (red arrow) surround the nests of cells. Magnification: 40X, Scale bar: $75 \mu \mathrm{m}$ 


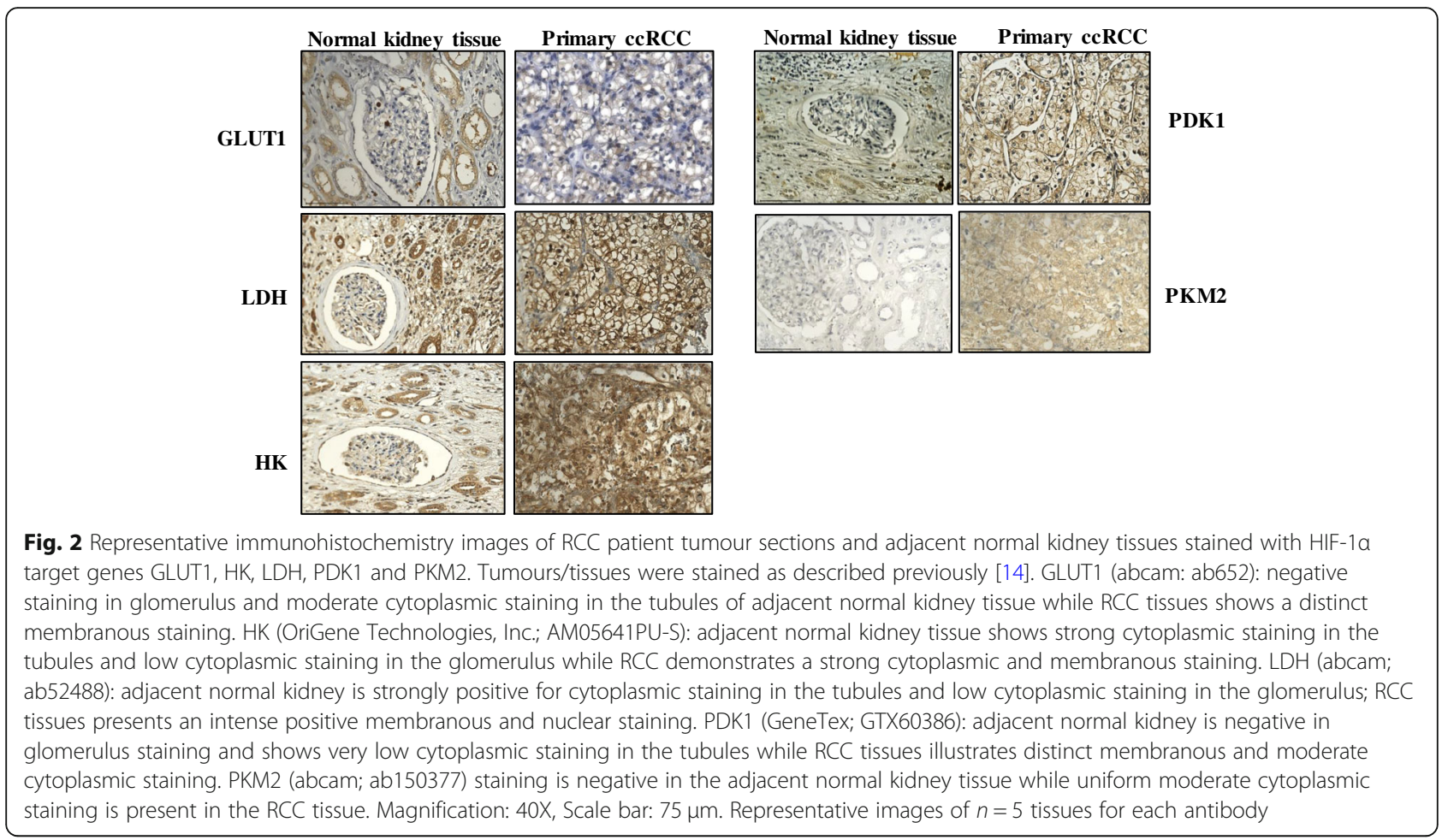

but lost as the tumour progresses [16]. By contrast, HIF$2 \alpha$ plays a critical role in RCC progression through its activating effects on c-Myc, epidermal growth factor receptor (EGFR), cyclin D, tumour protein p53, and mammalian target of rapamycin (mTOR) oncogenes, resulting in enhanced cell cycle progression and tumour growth [16-18]. Hence, ccRCC cases are divided into two groups. The first group has both HIF- $1 \alpha$ and HIF$2 \alpha$ expressed to drive tumour progression, whereas in the second group, the effect of only HIF- $2 \alpha$ prevails, particularly in vivo in rapidly proliferating tumours where access to nutrients is limited for tumour cells, resulting in enhanced tumour cell proliferation/angiogenesis and poor patient prognosis [16].

Next-generation sequencing has identified genes other than VHL that are commonly altered in RCC. Polybromo 1 (PBRM1) (41\%), BRCA1-associated protein 1 (BAP1) (15\%), and SET domain containing 2 histone lysine methyltransferases (SETD2) (19\%) have been mapped to chromosome 3p, similar to VHL [19]. PBRM1 is a subunit of SWI/SNF chromatin remodelling complex, BAP1 encodes the histone deubiquitinating enzyme BRCA1-associated protein, and SETD2 is a histone methyltransferase [20]. Studies have shown that other tumour suppressor genes, such as Wilms tumour 1 gene (WT1), the phosphatase and tensin homolog (PTEN), and tumour protein $p 53$, are also involved in the pathology of RCC $[21,22]$. Among these genes, p53 mutation has been shown as a prognostic indicator for RCC, with increased frequency of $p 53$ mutation reported with increasing grades and stages of RCC [23]. In this context, the correlation of $p 53$ mutation with disease-specific survival was reported in RCC patients [24].

\section{Epithelial-mesenchymal transition in ccRCC}

Epithelial-mesenchymal transition (EMT) is an embryonic development process that cancer cells utilize, whereby epithelial cells lose their epithelial polarity and attain a mesenchymal phenotype and shape in order to detach from primary sites to gain entry into surrounding tissue vasculatures for re-localization and spread into surrounding or distant sites [25]. The process is triggered by various stimuli received by the cancer cells from the tumour microenvironment, one of which is hypoxia-mediated HIF1- $\alpha$ activation, which plays a critical role in the initiation and orchestration of EMT [25]. The dissemination of cancer cells is facilitated by the loss of epithelial cell adhesion molecule E-cadherin and upregulation of E-cadherin repressors such as Slug, Snail, ZEB, and Twist, which are the hallmarks of the EMT process. An immunohistochemistry study on ZEB2 expression in $116 \mathrm{RCC}$ patients demonstrated high ZEB2 expression in RCC tumours that correlated with poor overall survival (OS) and progression-free survival (PFS) in RCC patients [26]. Similarly, enhanced Snail expression was frequent in high-grade RCC and associated with poor OS and PFS in RCC patients [27]. A recent study correlated EMT with an increased risk of 
recurrence and poor OS in RCC patients based on the expression of DCLK1 (a serine/threonine kinase involved in microtubule-mediated neuronal migration and morphogenesis) in RCC tumours [28]. In addition, DCLK1 was shown to be overexpressed and deregulated in $>93 \%$ of RCC tumours, and its knockdown by siRNA in RCC cells resulted in decreased expression of EMT and cancer stem cell (CSC) markers [29]. Further, the scoring of EMT based on the identification of spindle-shaped cells in tumours obtained from 47 RCC patients after nephrectomy was correlated with a shorter OS of 3-6 months in $96.4 \%$ patients compared to a longer OS of $>6$ months in $42.1 \%$ patients in whom spindle-shaped cells were absent [30]. A multivariate analysis of the expression levels of Clusterin, Twist, and C-reactive protein (CRP) in the tumours of 116 RCC patients obtained at nephrectomy independently predicted disease recurrence and recurrence-free survival established by the positive expression of each independent factor present in individual patient. Disease recurrence was observed in $7.7 \%$ of patients who were negative for any risk factor, $31.5 \%$ in patients who had one or two risk factors, and $60.9 \%$ of patients with three or four risk factors [31]. RCC tumour stage and histological grade, as well as sarcomatoid differentiation, are influenced by the expression of the transcription factor Snail. The conversion of ccRCC into sarcomatoid tumour is regulated by EMT by triggering $\mathrm{N}$-cadherin expression, dissociation of $\beta$ catenin from the cell membrane, and increased expression of Snail and Sparc proteins [32,33]. A recent study used an integration of omics and cellular/molecular biology assays on $26 \mathrm{RCC}$ patient samples to demonstrate a link between fibrosis and EMT correlating that to worse patient survival [34]. The above studies clearly indicate that EMT is a crucial driving force in RCC progression. Besides hypoxia-mediated HIF- $1 \alpha$ activation, several cytokines also contribute to the orchestration of EMT during RCC progression. Among these, IL-6, IL-8, IL-15, and tumour necrosis factor $\alpha$ $(\mathrm{TNF}-\alpha)$ play a prominent role in EMT facilitation via Akt/GSK-3 $\beta / \beta$-catenin signalling pathway [35-38]. Chronic oxidative stress also induces EMT characteristics in RCC cells [39]. Downregulation of the microRNA (miRNA)-200 family, which includes miR-200a/ $\mathrm{b} / \mathrm{c}, \mathrm{miR}-141$ and miR-429, is also involved in the EMT process in RCC [40]. A recent paper has shown that an immune suppressor cyclosporine in combination with transforming growth factor $\beta$ (TGF $\beta$ ) is able to induce EMT and CSC-like phenotypes in RCC cells [41]. Figure 3 demonstrates indication of EMT in RCC by illustrating enhanced staining of EMT-

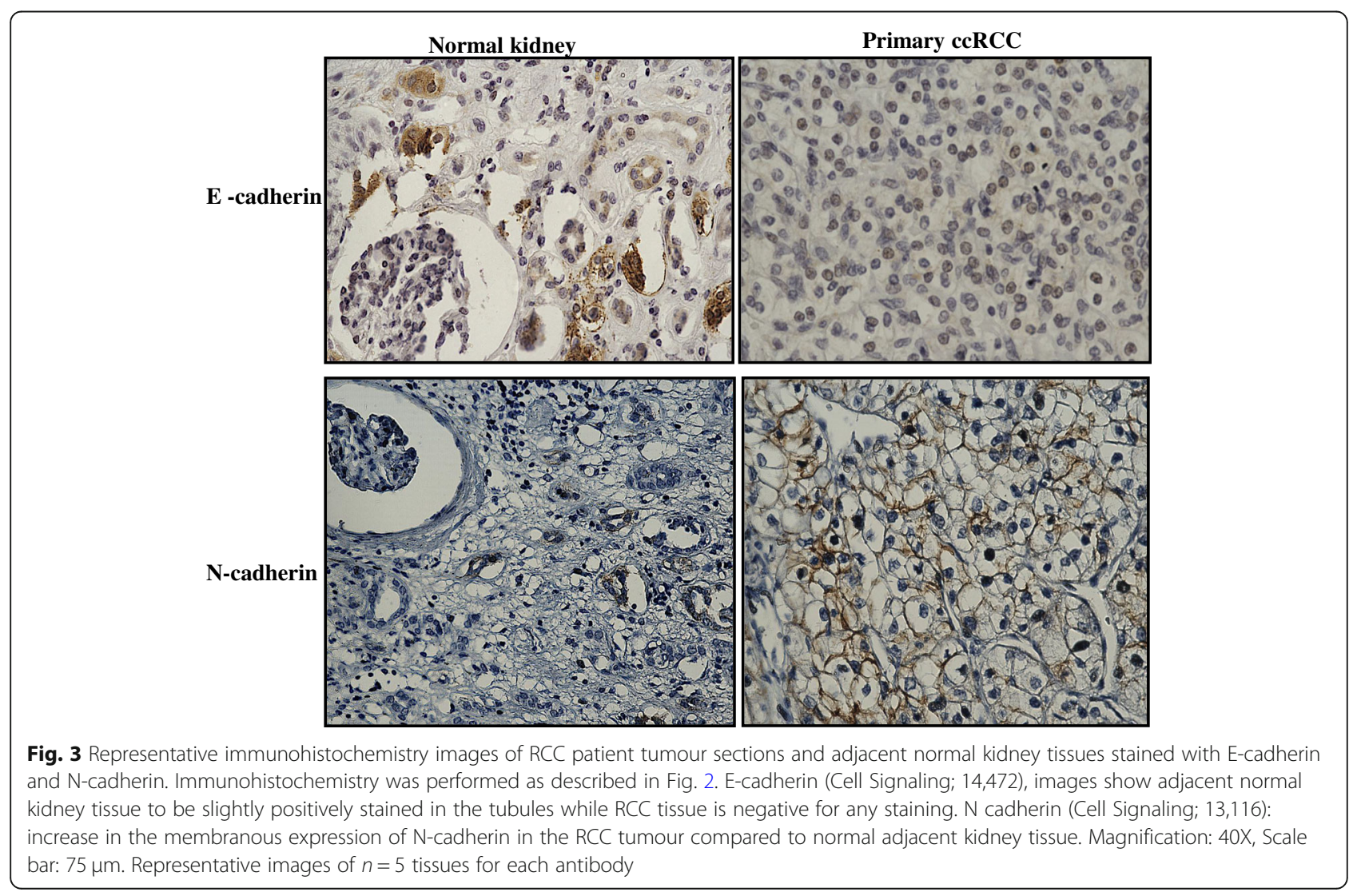


related $\mathrm{N}$-cadherin and low expression of E-cadherin in ccRCC tumours compared to adjacent normal kidney tissues.

\section{Cancer stem cells (CSCs) in RCC}

CSCs constitute a minor population of cells within tumours with a remarkable ability for tumour initiation and sustenance through infinite capacity for self-renewal and multi-lineage differentiation towards heterogeneous progenies [42]. RCC is known to be a heterogeneous tumour with the existence of both intra- and inter-heterogeneity. Heterogenous cell populations are functionally and phenotypically distinct and therefore display varying degrees of response and sensitivity to drugs, reducing the likelihood of treatment success. As such, CSC-like cells may be important determinants of clinical resistance and patient outcomes $[43,44]$. Further to that, the heterogeneity in CSCs may be modulated by a diverse range of factors, including genetic mutations, epigenetic changes, stimulus from the tumour microenvironment due to cellcell interaction, exposure to different cytokine milieus, and hypoxia $[45,46]$.

The mere observation that cancers can arise long after initial exposure to carcinogens implies that the carcinogenic event imposed by oxidative, genotoxic, or cytotoxic stress leading to damage-associated molecular pattern (DAMP) response may persist in the residual long-lived slowly proliferating stem cell population for an indefinite period ranging from months to years. This dormant response eventually triggered by unknown mechanism(s) gives rise to generations of daughter and differentiated cells, resulting in recurrent tumour masses [47]. Hence, recurrent or relapsed tumours that arise from CSCs consist of CSCs and a mixed population of cells, which create the full heterogeneous phenotype of the tumour. The induction of EMT giving rise to CSC-like cells was first shown in breast cancer, in which stimulation by TGF $\beta$ resulted in both EMT and CSC-like cells [48]. Consistent with this result, the introduction of mesenchymal markers Twist or Snail, responsible for the suppression of the epithelial adhesion molecule E-cadherin, led to an increase in the number of CSC-like cells in breast cancer [49]. Hypomethylation of genes specific for the transcription stem cell programme leads to EMT in cancer cells [50]. Moreover, E-cadherin transcriptional repressors Snail and Slug enforce CSC-like phenotypes and chemoresistance in ovarian cancer cells [51]. Recent studies have shown the existence of a side population (SP) cells in RCC tumours, a distinct type of CSCs, detected by the use of Hoechst 33342 dye (DNA binding dye) that displays a unique pattern by fluorescenceactivated cell sorting (FACS) [52]. However, no general applicable panel of markers for CSCs has been identified in RCC, and the characterization of putative CSCs varies in individual studies and is mostly based on their functional parameters. RCCs have been shown to display diverse CSC markers (such as CD44, CD133, CD105, CXCR-4, Oct4, Nanog, Klf4, and LIN28) and have a high expression of the ATP-binding cassette family of transporter proteins, such as MDR1 (P-glycoprotein) and $\mathrm{ABCB}$ transporters [53]. However, the proportion of cancer cells expressing different CSC markers remains uncertain and may not always reflect a true proportion of CSCs or have the CSC-like phenotype as described in other tumours [44, 54]. Furthermore, hypoxia plays a critical role in the conservation of EMT and CSC features in solid tumours. In RCC, hypoxia-induced HIF- $1 \alpha$ promoted EMT in RCC cell lines through increased expression of ZEB1 and ZEB2 and E2A immunoglobulin enhancer-binding factors E12/E47 (TCF3), which suppressed E-cadherin expression, leading to the attainment of a mesenchymal phenotype in these cells [55]. Tumour-infiltrating macrophages have been shown to induce EMT and CSC-like phenotypes in RCC cell lines and mouse xenografts [56]. Ectopic expression of retinoblastoma binding protein-2 (RBP2) promoted CSC phenotypes through EMT in RCC cells [57]. These observations indicate that the collaboration of EMT and CSC is crucial for RCC progression. Figure 4 demonstrates presence of $\mathrm{CD} 44, \mathrm{CD} 105$ and $\mathrm{CD} 133$ positive CSC staining in RCC tumours and adjacent normal kidney tissues.

\section{Hypoxia and its effect on the tumour microenvironment (TME)}

For cancer to adapt to low oxygen, tumour cells aberrantly develop new but defective and leaky blood vessels. The abnormal vasculature, together with the hypoxic microenvironment, promotes angiogenesis and inflammation, all of which lead to tumour progression and treatment resistance. Studies have highlighted that therapy resistance and cancer progression are not only regulated by tumour cells but also by the cells and components encompassing the tumour microenvironment (TME) [58]. Hypoxia induces genetic and proteome changes in tumours and associated cells in TME leading to accelerated cancer progression and induction of a more resistant tumour phenotype [59]. Hypoxia also decreases drug penetration and increase the expression of drug efflux transporters in tumours as well as tumour associated endothelial cells (TECs) [59]. In addition, the hypoxic environment promotes tumour cell glycolysis, which enhances lactic acid production, favouring a low $\mathrm{pH}$ TME that suppresses immune cell functions such as proliferation and cytotoxicity [60].

One cell population that thrives under hypoxic conditions in tumours are TECs. These cells are an important component of RCC TME and are key to progression and 


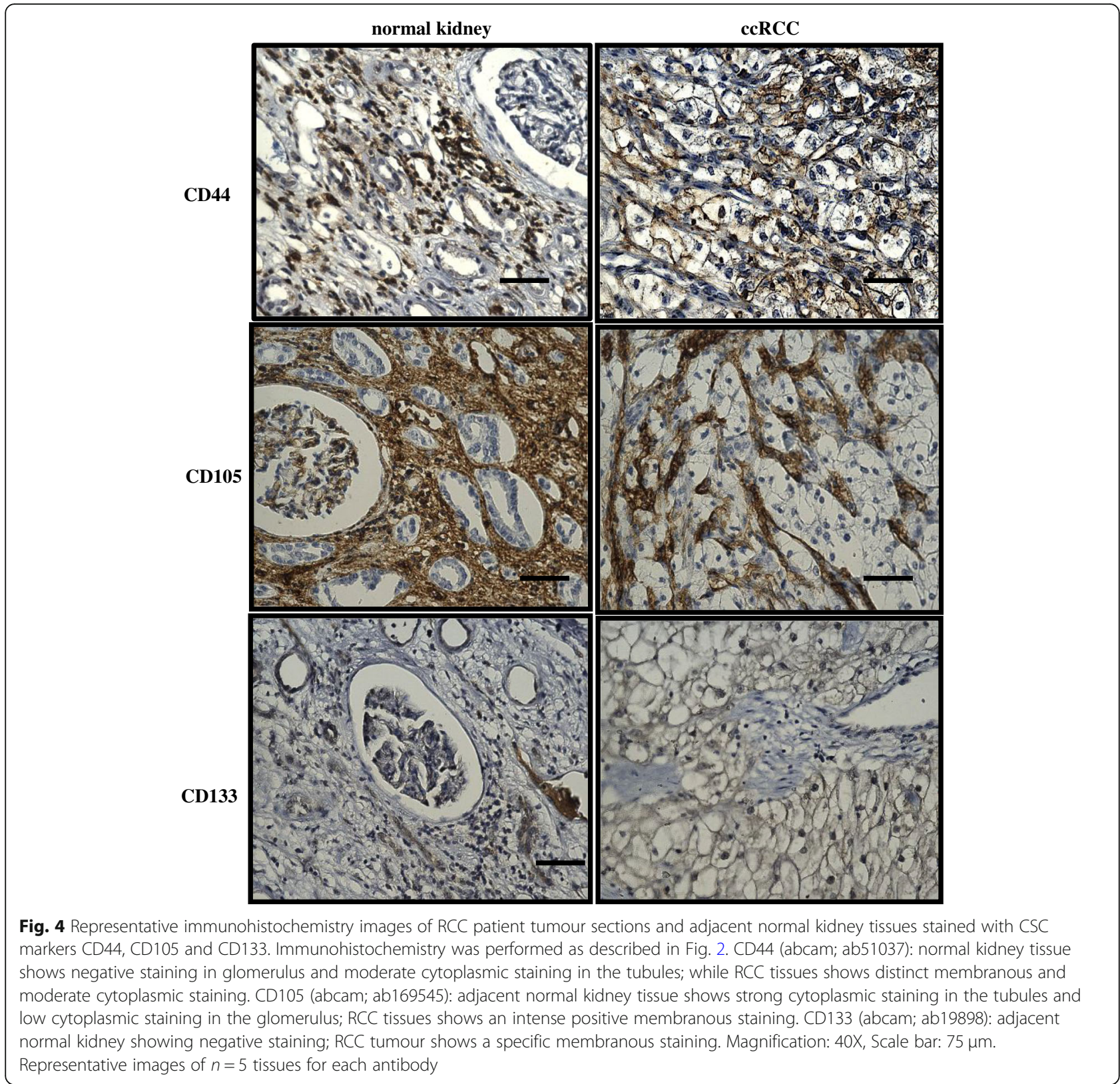

therapy resistance. Higher levels of circulating endothelial cells have been noted in mRCC patients treated with sunitinib who acquire resistance [61]. Contrary to the popular belief that TECs are homogenous and cannot proliferate in $\mathrm{RCC}$, these cells are capable of hyperproliferation and display metabolic, genetic and morphological abnormalities compared to normal endothelial cells (NECs) [62]. TECs isolated from human tumour xenografts of RCC, melanoma and liposarcoma displayed chromosomal irregularities associated with aneuploidy $[63,64]$. These aneuploid TECs in TME were surrounded by pimonidazole-positive areas, indicating association of hypoxia with aneuploidy [64]. The same study showed that aneuploidy could also be induced in NECs in response to hypoxia, which was inhibited by inhibitors of VEGFR2 or reactive oxygen species (N-acetyl-Lcysteine) [64]. These studies indicate that hypoxia modulates phenotypic and genotypic characteristics of TECs via VEGF and ROS expression in TME and may transform NECs to TECs to favour tumour progression.

A recent study has shown TECs isolated from hypoxic highly metastatic tumours contained more aneuploid cells, had enhanced proliferative and invasive capacity and had enhanced mRNA expression of proangiogenic (VEGF, VEGFR1/2, HIF-1 $\alpha$ ) and stemness 
genes than TECs derived from low metastatic tumours [65]. In addition, TECs from different tumours (melanoma, liposarcoma, RCC, glioma, breast and hepatocellular carcinoma) overexpress proangiogenic growth factors and receptors suggesting an autocrine loop for sustenance in an activated mode in TME [66]. Compared to NECs, TECs are also more resistant to serum starvation and cytotoxic drugs [66-69]. TECs in RCC express PAX2 and HLA-G, two embryonic markers generally expressed in renal tumours $[70,71]$. The expression of embryonic markers in RCC TECs may indicate their dedifferentiation status different from adult or tumour stem or progenitor cells [66]. These functional alteration in TECs may result from constitutively activated signalling pathways, such as PI3K/Akt [72], Cox-2 pathways [73] and downregulation of anti-angiogenic factors such as thrombospondin-1 (TSP-1) and endostatin, [72, 74], responsible for the induction of resistance to chemotherapeutic and antiangiogenic drugs.

Further to that, recent studies have shown that CSCs in leukemias, breast and ovarian cancer to differentiate into endothelial cells $[75,76]$. In RCC, $\mathrm{CD}_{105^{+}}$and $\mathrm{CD}_{133^{+}} \mathrm{CSCs}$ were noted to generate endothelial cells in vivo [77, 78]. Considering that hypoxic cancer cells are poorly differentiated and express markers of CSCs $[79,80]$, it can be postulated that hypoxic RCC with CSC phenotype may have the potential to initiate and promote vasculogenesis to sustain and accelerate tumour growth. In that context, hypoxia induced increased expression of HIF- $1 \alpha$ and HIF- $2 \alpha$ has been noted in neuroblastoma and glioma CSCs $[81,82]$. Both HIF- $1 \alpha$ and HIF- $2 \alpha$ are also associated with hypoxia-induced expression of CD133 and knocking down of either HIF$1 \alpha$ [83] or HIF-2 $\alpha$ [84] was shown to reduce hypoxiainduced CD133 expression in glioma CSCs.

Along with irregular blood vessels, hypoxia can also lead to blocked lymphatic drainage with increased interstitial pressure [59]. This interstitial fluid pressure within the tumour can interfere with tumour cell's drug uptake by counteracting the passage of drug into the tumour cells. Cancer-associated fibroblasts (CAFs) in the TME are associated with these pressure forces within the tumour, and some studies have successfully demonstrated improved uptake of cytotoxic drugs by targeting CAFs [85]. In mRCC, activation of fibroblast activating protein was shown to induce aggressive phenotype in RCC via CAFs-mediated recruitment of macrophages leading to remodelling of TME [86]. In addition, a recent study has identified a distinct angiogenesis ${ }^{\text {high }}$ macrophages ${ }^{\text {low }}$ fingerprint in a cluster of $\mathrm{RCC}$, which may prove crucial for predicting anti-TKI/antiangiogenesis treatments [87]. Other studies have also linked CAFs with resistance to antiangiogenic drugs $[88,89]$. In addition, TECs have immune regulatory roles as they are directly involved in affecting $\mathrm{T}$ cell priming and migration, modulating immune cell trafficking by favouring infiltration in tumours of immune suppressive (such as Tregs, MSDCs, TAMs) rather than immune effector cells $\left(\mathrm{CD} 8^{+}\right.$and $\mathrm{CD} 4^{+}$ cells) [90]. Hence, it is important to characterise the cancer promoting functions of hypoxia-modulated TECs to develop new strategies targeting TME associated TECs in combination with tumour cells.

RCC has long been recognised as an immunogenic tumour due to a substantial amount of immune cell infiltration in the tumours [91]. However, the mere presence of immune cells in the tumours (TILs) does not indicate that these immune cells are active to mount an anti-tumour response. A recent study on the peripheral blood mononuclear cells (PBMCs) of 90 RCC patients showed increased expression of PD-1 on CD14 bright myelomonocytic cells, effector $\mathrm{T}$ cells and natural killer (NK) cells, which correlated with disease stage. The PD-1 expression on immune cells was significantly reduced after surgery of primary tumours $[92,93]$. In another study on the PBMC of 40 RCC patients identified $\mathrm{CD} 8^{+} \mathrm{PD}-1^{+} \mathrm{TIM}-3^{+} \mathrm{Lag} 3^{+}$ TILs, CD $4^{+} \mathrm{ICOS}^{+}$TILs and $\mathrm{CD} 25^{+} \mathrm{CD} 127^{+}$Foxp $3 / \mathrm{Helios}^{+}$ GITR $^{+}$Tregs phenotype to be associated with high risk of disease progression after nephrectomy within the same year [94]. In a subsequent study it was shown the patients having high levels of $\mathrm{CD}^{+} \mathrm{PD}-1^{+} \mathrm{TIM}^{+} \mathrm{LAG}^{+}$in $\mathrm{PBMCs}$ responded significantly well to nivolumab (anti-PD-1) but not to everolimus in terms of overall and progression-free survival, suggesting a specific therapeutic role of nivolumab in these patients [95]. These data suggests the potential of TIM3 and LAG3 as additional checkpoint inhibitors in RCC management. Very recently, tumour-educated B cells (TEB) within the RCC TME were shown to play a key role in RCC progression and therapy resistance $[96,97]$.

\section{The role of non-coding RNAs (miRNAs) in RCC}

Recent studies have identified circulating non-coding RNAs such as miRNAs as potential blood-based biomarkers for early-stage diagnosis, prediction of prognosis and treatment response in RCC [98]. Among the different miRNAs described in RCC, miR-210 was shown by several studies to hold promise as a potential early-stage biomarker as its expression level was significantly enhanced in malignant tissues compared to healthy adjacent parenchyma, and its level in the serum of RCC patients was significantly high compared to healthy controls $[14,99-102]$. According to these studies, the serum miR-210 levels could differentiated RCC patients from healthy controls however, both sensitivity and specificity of miR-210 varied substantially between the studies. Other studies have shown regulation of miR-210 by hypoxia, showing upregulation of miR-210 in response to hypoxic conditions in RCC cell lines, 
suggesting a close relationship of miR-210 with RCC development [101-103].

Apart from miR-210, combination of miR-210 and miR-378 provide greater discriminatory ability of identifying RCC patients from healthy individuals [14]. However, significant enhancement in the serum levels of miR-378 levels have been controversial with some studies showing its reduced serum levels in RCC patients compared to healthy controls [104]. Apart from that, combination of miR-378 and miR-451 in serum of RCC patients could provide sensitivity of $81 \%$ and specificity of $83 \%$ compared to healthy individuals [105].

Further to that, a miR diagnostic signature for RCC patients based on serum expression of different miRNA consisting of miR-378, miR-193a-3p, miR-362, miR-572 and miR-28-5p was developed [104]. However, its clinical utility in patients could not be conclusively analysed as the expression of these miRNAs were not deduced in corresponding tissues. In addition, the expression of several other miRs (extensively discussed in [98]) was noted to be elevated in the serum of RCC patients compared to control individuals but none showed prognostic utility in a clinical setting.

\section{Treatment of metastatic RCC}

Recent advances in understanding the molecular and genetic characteristics of RCC have led to the development of many novel drugs, leading to improved clinical outcomes. Nivolumab, cabozantinib, and lenvatinib plus everolimus have gained Food and Drug Administration (FDA) approval in the last 2 years. In the following sections, we outline the currently understood innate and acquired drug resistance mechanisms in RCC and discuss the current novel approaches used to overcome such resistance.

The selection of treatment for RCC patients depends on the prognostic risk factors. These risk factors guide clinical trial design, patient counselling, and risk-specific treatment decisions. Five prognostic factors, including haemoglobin < lower limit of normal (Normal for men: 13.5-17.5 g/dL and normal for woman: $12-15.5 \mathrm{~g} / \mathrm{dL}$ ), time from diagnosis to systemic treatment $<1$ year, calcium $>10 \mathrm{mg} / \mathrm{dL}, \mathrm{LDH}>1.5 \mathrm{x}$ upper limit of normal were correlated with overall survival (OS) in metastatic RCC (mRCC). These factors were integrated into a prognostic risk score called the Memorial Sloan- Kettering
Cancer Center (MSKCC) score [106]. However, when VEGF-TKIs revolutionized the treatment options of mRCC, there was a need for a new prognostic score, and the International Metastatic RCC Database (IMDC) was founded. Based on the median OS, the IMDC prognostic score has three risk groups: favourable, intermediate, and unfavourable. Treatment options for $\mathrm{mRCC}$ follow the IMDC prognostic risk factors. Table 1 outlines the IMDC criteria for prognostic evaluation.

Before the development of advanced therapeutics, such as VEGF-TKIs and immunotherapy, the treatment for mRCC revolved around the use of cytokines such as interleukin 2 and IFN- $\alpha$, which were effective only in $5-15 \%$ of patients [107]. However, cytokine therapy alone was not enough to overcome the complex vascularization and metastatic biology of RCC regulated by HIF-induced downstream angiogenic signalling pathways [108]. Hence, there was a need for antiangiogenic treatment that would target VEGF and mTOR pathways and potentially control angiogenesis to provide better OS and PFS in advanced RCC patients. Many observational studies have validated the significant role of anti-angiogenesis therapy in RCC [109-111]. However, since 2004, the introduction of more target-specific therapies and immunotherapy has created a paradigm shift in the treatment of RCC.

\section{Angiogenesis inhibitors}

Antiangiogenic VEGF-TKIs, such as sunitinib and pazopanib, are currently used as the first-line treatments in RCC. Sunitinib showed a high response rate of 8.3 months of PFS in a multicentre phase II trial [112]. The encouraging objective response based on phase I and phase II trials led to a crucial randomized phase III trial in 750-treatment naïve advanced RCC patients. The results demonstrated superior efficiency of sunitinib (11 months) over IFN- $\alpha$ (5 months) in PFS and supported its use as the first-line treatment for mRCC $[113,114]$. The median overall survival in the sunitinib-treated patients was also higher than in the IFN- $\alpha$ group, being 26.4 versus (vs.) 21.8 months, respectively, and the common toxicity demonstrated in patients included hand and foot syndrome, diarrhoea, and hypertension [114]. In phase III trial, pazopanib showed a similar result of a median PFS of 11.1 vs. 2.8 months compared with a placebo in the treatment-naïve subpopulation, and 7.4 vs 4.2

Table 1 IMDC prognostic score risk groups

\begin{tabular}{lll}
\hline Number of risk factors & Risk Group & Median overall survival (months) (95\% Cl) \\
\hline 0 & Favorable/Good & $43.2(31.4-50.1)$ \\
1 to 2 & Intermediate & $22.5(18.7-25.1)$ \\
3 to 6 & Unfavorable/Poor & $7.8(6.5-9.7)$ \\
\hline
\end{tabular}

The above table describes the criteria for the risk groups depending on the number of risk factors and the median OS of the patients. The six risk factors taken into consideration include low Karnofsky performance status $(<80 \%)$, low serum hemoglobin, high serum calcium level ( $>10.2 \mathrm{mg} / \mathrm{dL})$, increased neutrophil and platelet count $\left(7 \times 10^{9} / \mathrm{L}\right.$ and 400,000 respectively) and time from diagnosis to the treatment $<1$ year 
months compared to cytokine pre-treated patients [115]. The overall survival in pazopanib-treated patients was 22.9 months, and the most experienced adverse effects (AEs) were hypertension, vomiting, diarrhoea, anorexia, and hair colour changes [116]. Owing to the similar PFS benefits, two randomized controlled studies COMPARZ trial and PISCES study were undertaken to compare sunitinib and pazopanib to find the optimal first-line therapy. While the primary endpoint of the COMPARZ trial was PFS, the PISCES study assessed patient preference between pazopanib and sunitinib as the primary endpoint. Pazopanib emerged non-inferior to sunitinib in terms of PFS and overall survival, with $70 \%$ of patients preferring pazopanib to sunitinib $[117,118]$. The two pivotal studies have placed sunitinib and pazopanib at par as standard front-line treatments for $\mathrm{mRCC}$ across the world. In terms of direct transferability of these clinical trial results in patient care, many recent retrospective studies have associated sunitinib with better overall survival compared to pazopanib [119-121].

Sorafenib and axitinib are the other VEGF-TKIs that have been tested as first-line treatments in advanced RCC. First introduced in 2004, sorafenib is an antiproliferative and antiangiogenic agent and a multi-target VEGF-TKI against VEGFRs (1-3), platelet derived growth factor- $\beta$ (PDGRF- $\beta$ ), c-Kit protein (c-Kit), FMSrelated receptor tyrosine kinase 3 (FLT-3), Raf kinases (C-Raf, B-Raf), mutant B-Raf, rearranged during transfection (RET), and RET/papillary thyroid carcinomas (PTC) $[122,123]$. An open-label phase II trial evaluating sorafenib vs. IFN- $\alpha$ for PFS, overall response, and adverse events was conducted in 189 patients with untreated advanced RCC. It was found that sorafenib did not improve the PFS when compared to IFN- $\alpha$ [124]. However, according to the TARGET trial, a phase III randomized placebo-controlled trial in 903 therapyfailed patients, sorafenib improved progression-free survival (5.5 vs. 2.8 months) [125]. Even though the European Society for Medical Oncology (ESMO) guidelines included sorafenib as a first-line treatment, this was not endorsed by National Comprehensive Cancer Network $(\mathrm{NCCN})$ guidelines $[126,127]$. A phase III SWITCH trial showed that there was no significant difference in the PFS between the sequential treatment of sorafenib followed by sunitinib and vice versa. This followed another phase III trial, SWITCH-II, which compared the total progression-free survival (tPFS) between sorafenibpazopanib (So-Pa) and pazopanib-sorafenib (Pa-So). However, So-Pa did not meet the total PFS (8.6 vs 12.9 months) criterion when compared with $\mathrm{Pa}-\mathrm{So}$ in 377 randomised patients [128].

Axitinib, a tyrosine kinase inhibitor of VEGFRs 1-3, is used as a second-line option for mRCC. However, it was evaluated as a first-line agent and compared with sorafenib in a phase II trial in 192 patients across 13 countries. The primary endpoint was PFS. Axitinib did not demonstrate an increase in the PFS when compared to sorafenib. Although axitinib did not show any superiority over sorafenib, it is included as a first-line treatment option in NCCN guidelines (category 2A). The guidelines take into consideration that axitinib has demonstrated clinical activity and an acceptable safety profile $[126,129]$.

Cabozantinib is a small molecule oral VEGF-TKI. The FDA first approved its use in November 2012 to treat metastatic medullary thyroid cancer. It was approved in April 2016 as a second-line drug treatment of patients with RCC who had previously received antiangiogenic therapy [130]. Cabozantinib is different from other VEGFTKIs as it targets multiple tyrosine kinases implicated in mRCC in addition to VEGFR, such as mesenchymalepithelial transition factor (MET), anexelekto (AXL), RET, KIT, and FLT3 [131]. Pre-clinical studies have shown an increase in the expression of MET and AXL in RCC tumours when exposed to chronic sunitinib therapy; these are important resistance mechanisms in $\operatorname{RCC}[57,132]$. This pre-clinical breakthrough gave a strong rationale for cabozantinib to be studied clinically in the METEOR trial. The phase III randomised trial compared cabozantinib and everolimus and included 658 patients who progressed with the cancer after treatment with at least one VEGFTKI. The primary endpoint was mPFS, whereas the secondary endpoint was OS and overall response rate (ORR) and safety. The study achieved its primary endpoint with cabozantinib showing a superior outcome to everolimus (7.4 vs 3.8 months). The rate of progression of the disease or death was $42 \%$ lower in cabozantinib than with everolimus [133]. A follow-up study after 1 year observed an improved median OS of 21.4 months in cabozantinib-treated patients in comparison to 16.5 months with everolimus. The ORR was $17 \%$ with cabozantinib vs $3 \%$ with everolimus. The most common adverse event noted was hypertension [134].

Similar to the METEOR study, the CABOSUN study was undertaken to compare the clinical benefits of cabozantinib with sunitinib in 157 treatment-naïve patients with intermediate to poor IMDC risk. Patients treated with cabozantinib showed improved PFS (8.6 vs. 5.3 months) and ORR (46\% vs. 18\%) [135]. A superior OS was achieved in patients treated with cabozantinib; however, it was not significant (26.6 vs. 21.2 months). With cabozantinib, the rate of disease progression or death decreased by $34 \%$. Similar grade 3 or 4 adverse events were observed for patients with cabozantinib and sunitinib and included diarrhoea, fatigue, hypertension, palmarplantar erythrodysthesia, and hematologic adverse events (67\% vs. 68\%, respectively) [136]. Based on the CABOSUN results, NCCN and ESMO recommended 
cabozantinib as a first-line treatment option for patients with poor to intermediate IMDC risk (Category 2A). This recommendation was made at a lower level than the category 1 agents pazopanib, sunitinib, and bevacizumab plus IFN- $\alpha$ [126, 137]. Cabozantinib has recently been shown to have enhanced efficacy in a retrospective cohort study investigating naïve and refractory metastatic non-clear RCC belonging to all IMDC model risk groups [138].

\section{Immune checkpoint inhibitors}

Immunotherapy has been an integral part of RCC treatment for decades. RCC is categorized as an immunogenic tumour based on its response to immunotherapy and high level of $\mathrm{T}$ cell infiltration, including dendritic cells, natural killer $\mathrm{T}$ cells, macrophages, and memory cells, along with increased cytokine secretion [139]. More than a decade ago, treatment of RCC patients heavily depended on interleukin-2 (IL-2) and IFN- $\alpha$, which not only yielded a low efficacy and overall response but also was also associated with significant toxicity. Rapid development in immune checkpoint inhibitors in the past decade has helped fill the gaps left by IL- 2 and IFN- $\alpha$.

\section{Nivolumab and Ipilimumab}

Recently, Nivolumab, an anti-programmed cell death protein 1(PD-1) monoclonal antibody, was the first immune checkpoint inhibitor approved by the FDA in 2015 for RCC patients based on a phase III clinical trial CheckMate 025. Nivolumab exploits a negative co-stimulatory signal meant to mitigate $\mathrm{T}$ cell receptor (TCR) signalling. The trial compared nivolumab with everolimus and was carried out in 821 patients previously treated with one or two antiangiogenic therapies. The overall survival of the patients treated with nivolumab was significantly higher (25 vs.19.6 months) than those treated with everolimus, and the most common adverse event noted was fatigue. Another less successful checkpoint inhibitor, ipilimumab, designed to reduce the inhibitory effect of cytotoxic $\mathrm{T}$ lymphocyte-associated protein 4 (CTLA-4) resulted in significant autoimmune toxicities in 61 patients [140].

Although nivolumab in monotherapy had shown improved overall survival in the CheckMate 025 trial, the median PFS (mPFS) was not much superior to everolimus (4.6 vs. 4.4 months). This observation, along with the fact that ipilimumab had shown limited efficacy and significant toxicity in patients, supported the rationale for combining both nivolumab and ipilimumab. This combination produced objective responses in RCC patients in a pilot study that led to a phase III trial, CheckMate 214, comprising 1096 treatment-naïve patients
[141]. The primary endpoints were overall survival, objective response rate, and progression-free survival. After a median follow-up of 25.2 months in intermediate and poor-risk patients, the 18 -month OS rate was $75 \%$ with the combination immunotherapy and $60 \%$ with sunitinib. The median overall survival was not reached with the nivolumab-ipilimumab combination vs. 26 months with sunitinib. The mPFS was 11.6 months in the combined immune checkpoint inhibitors as compared to 8.4 months in sunitinib [142]. Further evaluation of patientreported outcomes showed fewer symptoms and improved health-related quality of life (HRQoL) with combination therapy than sunitinib in intermediate or poorrisk patients with RCC [143]. The encouraging findings that suggested a superior efficacy of nivolumab and ipilimumab over sunitinib led the FDA to approve this double immune checkpoint blockade in April 2018 for RCC patients with intermediate or poor-risk features.

\section{mTOR inhibitors}

The mammalian target of rapamycin (mTOR), a member of the phosphatidylinositol-3-kinase (PI3K) family, is an important component of intracellular signalling pathways that activates growth factors and regulates cellular metabolism, proliferation, and angiogenesis. Although everolimus and temsirolimus have shown to be effective against RCC in patients, only temsirolimus gained approval to be used as a first-line agent to treat patients with unfavourable risk factors. Temsirolimus was approved after a phase III Global Advanced Renal Carcinoma trial, conducted in 626 treatment naive patients with poor prognostic features. This trial showed greater OS (10.9 months) in comparison with IFN- $\alpha$ alone (7.3 months) or as a combination therapy (8.4 months). The study also reported that temsirolimus had a higher PFS (3.8 months) than IFN- $\alpha$ (1.9 months) [144]. Although these phase III trial results were promising, temsirolimus is not a common treatment method in a regular clinical setting [127]. Interestingly, there are no clear studies comparing temsirolimus with the existing first-line VEGF-TKIs. However, RECORD-3, a phase II study that was conducted in 238 patients, compared the sequence of everolimus followed by sunitinib and vice versa. The overall survival did not support the use of everolimussunitinib sequential therapy [145].

\section{Pembrolizumab plus axitinib}

Recently, a phase III trial, was conducted with 861 patients randomly receiving axitinib plus pembrolizumab, a PD-1 inhibitor, and sunitinib monotherapy in previously untreated patients with $\mathrm{mRCC}[111,146]$. The primary endpoint mPFS was significantly higher with the pembrolizumab plus axitinib combination than with sunitinib (15.1 vs 11.1). The risk of progression or death was 
reduced by $47 \%$ with the combination therapy. This benefit was observed across all IMDC risk groups. The most common grade 3 and 4 AEs in both groups were diarrhoea and hypertension. Based on the benefits and tolerability of this combination, FDA approved this therapy for treatment-naïve $\mathrm{mRCC}$ patients regardless of the IMDC risk stratification or programmed death-ligand 1 (PDL1) status. Recently, the investigators published a subgroup study for the combined intermediate/poor risk group and patients with sarcomatoid features. The observed benefits for the subgroup of improved OS, ORR, PFS, and complete response were consistent with those obtained for the total population [111].

\section{Avelumab plus axitinib}

Axitinib also showed encouraging results with avelumab, a PD-L1 inhibitor, when compared with sunitinib monotherapy in a phase III JAVELIN Renal 101 trial. Eight hundred and eighty six randomised previously untreated patients with RCC were assigned to receive the combination therapy or the standard of care sunitinib. The primary endpoints were PFS and OS among the patients with PD-L1-positive tumours. Interestingly, the primary endpoint of longer PFS was achieved in the combination arm irrespective of the PD-L1 expression status (13.8 vs. 8.4 months). In PD-L1-positive tumour patients, the ORR was also higher than with sunitinib $(55.2 \%$ vs. 25.5\%). The grades 3 and 4 AEs were similar in both arms, with the most common AEs reported being hypertension, diarrhoea, fatigue, and palmar-plantar erythrodysesthesia [147]. Based on the positive results of this trial, in May 2019, the FDA approved the combination of avelumab plus axitinib to be used as a first-line treatment for patients with advanced RCC.

The treatment approaches for $\mathrm{mRCC}$ have been revolutionized twice, once more than a decade ago with the availability of targeted therapy and then in 2015 with the advent of immune checkpoint inhibitors. The recent new trials combined the two strategies (VEGF inhibitor and immune checkpoint inhibitors), which have proven to have significant benefits. The ongoing clinical trials with new therapeutic approaches have been reviewed in detail in the latter part of the review. In the last decade, the treatment paradigm has shifted, increasing the median survival of mRCC patients to about 33 months, and the ultimate goal of the new approaches in RCC treatment will be the long-term survival of patients.

\section{Lenvatinib and everolimus}

A combination treatment with approved drugs is typically considered to have the potential to improve response rates and overall survival because they often exert a synergistic effect [148]. A combination of a VEGFR and mTOR inhibitor has always been an attractive therapeutic strategy in the treatment of mRCC. Many combinations were previously tried that resulted in higher toxicity without additional antitumour benefits. However, more recently, in a landmark study, a PFS advantage was observed using VEGFR and mTOR inhibitors in combination. In a phase II trial, 153 patients previously treated with VEGFRVEGF-TKI were assigned to receive lenvatinib and everolimus either as a single agent or in combination. The primary endpoint of prolonged PFS was achieved in the combination therapy as compared to everolimus alone (14.6 vs. 5.5 months). The most common AEs were fatigue, hyporexia, and vomiting. However, the patients who received combination therapy experienced significant toxicity as compared to the single agent everolimus $(71 \%$ vs. $50 \%$ ). Despite the toxicity issues, the FDA approved the combination of lenvatinib plus everolimus in May 2016 for the treatment of patients with RCC who have received prior antiangiogenic therapy [149, 150]. The current first-line treatment and the subsequent treatment approaches after disease progression are outlined in Tables 2 and 3. Tables 4 and 5 describe some of the clinical trials ongoing in RCC patients.

\section{Drug resistance in RCC}

The last decade has seen tremendous improvement in terms of the available treatment options for mRCC. The 5 -year survival rates have improved in patients with advanced RCC over the last 10 years; yet, a large percentage of them do not respond due to innate or acquired resistance. Primary resistance is characterized as an immediate lack of response to the therapeutic compound, which occurs when the tumour cells do not express the intended target or are intrinsically resistant cells, leading to an immediate lack of response to the therapeutic compound. By contrast, acquired resistance occurs while the patient is still on treatment over the course of the disease, and tumours are able to activate the target pathways by complementary mechanisms. It is characterized as disease progression and cancer relapse after the initial tumour regression. Over the past few years, many studies have tried to examine the underlying cause of drug resistance in RCC. A comprehensive evaluation of the mechanisms of VEGF-TKI and ICI resistance will help in formulating useful knowledge about developing effective treatment strategies for patients with advanced RCC.

\section{Hypoxia and drug resistance}

RCC is a heterogeneous tumour with widely differing blood flow conditions across tissues. Two forms of intratumour hypoxic conditions exist in the tumour: chronic and transient or acute hypoxia [151]. Acute hypoxia occurs due to temporary blood vessel occlusion in the inner core of tumours, whereas chronic hypoxia results from low availability of oxygen in tumour regions at a distance 
Table 2 Current updated front line treatment for mRCC based on the IMDC prognostic score risk factors

\begin{tabular}{|c|c|c|}
\hline Front line therapy & Limited Disease Burden/ asymptomatic & Substantial disease burden/ symptomatic \\
\hline \multicolumn{3}{|l|}{ IMDC risk } \\
\hline \multirow[t]{3}{*}{ Good/Favourable risk } & Pazopanib $^{a}$ & Nivolumab $b^{b}$ plus ipilimumabc \\
\hline & Sunitinib ${ }^{a}$ & Pembrolizumab $b^{b}$ plus axitinib ${ }^{a}$ \\
\hline & & Avelumab ${ }^{d}$ plus axitinib \\
\hline Intermediate and poor risk & $\begin{array}{l}\text { Nivolumab } b^{b} \text { plus ipilimumab }{ }^{c} \\
\text { Pembrolizumab }{ }^{b} \text { plus axitinib } \\
\text { PD1/PD-L1 immune checkpoint inhibitor contraindications } \\
\text { Pazopaniba, Sunitinib } b^{a} \text {, Cabozantinib }\end{array}$ & \\
\hline
\end{tabular}

${ }^{\mathrm{a} V E G F R-T K I},{ }^{\mathrm{b}}$ Anti-PD-1 antibody, ${ }^{\mathrm{C} A n t i-C T L A-4}$ antibody, ${ }^{\mathrm{d}}$ Anti-PD-L1

from blood vessels, especially in large tumours. Hypoxia can lead to impaired cellular responses, advanced and dysfunctional vascularisation along with metastasis contributes to therapy resistance by inducing cell quiescence. Clinical resistance is an important and intricate phenomenon in RCC resulting from several underlying mechanisms. Hypoxia is one of the key factors in RCC, correlating with poor prognosis in RCC progression and affecting activities at the cellular level, resulting in resistance of the tumour cells to VEGF-TKIs and ICIs.

ICI-mediated antiangiogenic therapy suppresses the production of proangiogenic factors or inhibits their binding to their respective receptors, subsequently halting angiogenesis; hence, they were approved for the treatment of mRCC [152]. However, sustained treatment with antiangiogenic therapy consequently leads to the development of secondary hypoxia caused by decreased vasculature due to drug treatment. Tumour cells can adapt to sustained hypoxia through coordinated and complex intracellular signalling responses, resulting in several VEGF- and PDGF-independent proangiogenic factors, such as EGFR, PIGF, FGF2, erythropoietin (EPO), TGF- $\alpha$, IL-6, IL-8, which induce acquired resistance and therapy failure, most importantly, activation of the HIF pathway [153].

Studies have shown overexpression of FGF 1/2, ephrin A1 and A2 (EFNA1/2) and angiopoietin 1 and 2 (Ang 1/2) as a direct result of hypoxia induced by antiangiogenic treatments. FGF can prompt endothelial cells to proliferate and form endothelial tubules in the presence of VEGF-TKI [154]. FGF/FGFR pathway regulates intracellular signalling cascades, such as MAPK/ERK, PI3K/Akt,
STAT, inositol triphosphate, and diacylglycerol protein kinase $\mathrm{C}$, and aberrant signalling in these pathways is linked to the development of sunitinib resistance [155]. Inhibition of these targets with lenvatinib plus everolimus has demonstrated superior activity in patients previously treated with sunitinib [149]. The Ang/Tie signalling pathway is another important and alternative angiogenic pathway in RCC. The pathway modulates endothelial cell survival and vascular maturation. Ang 2 levels are decreased in patients responding to sunitinib therapy; however, it is increased when the patients start showing resistance to sunitinib [156]. CovX-bodies (protein-antibody construct) are a new class of biotherapeutics that have demonstrated decreased tumour vessel density when combined with sunitinib and sorafenib [157].

Recently, the interaction between the immune system and angiogenesis has gained momentum. IL-6, known to cause resistance to IFN- $\alpha$, has also been shown to be an inducer of VEGF-TKI resistance and a potent activator of AKT-mTOR and signal transducer and activator of transcription 3 (STAT3) pathway, along with HIF-2 $\alpha$, all of which leads to VEGF expression [158]. IL-8, an important proangiogenic factor, is known to have high expression in patients resistant to VEGF-TKIs, which enhances angiogenesis via autocrine activation of VEGF R-2 and proliferation of endothelial cells [159]. Both IL6 and IL-8 are poor prognosis indicators in RCC and can serve as a therapeutic target to reverse VEGF-TKI resistance, as shown in several studies [158-160]. Similarly, PIGF, a VEGF homolog known to increase angiogenesis by binding to VEGFR-1 is expressed by tumour, proangiogenic, inflammatory, stromal, and endothelial

Table 3 Treatment approach for subsequent therapy in patients after the progression of disease with therapy failure

Disease progression with no previous exposure to anti-angiogenic therapy

Disease progression with VEGFR inhibitor plus immunotherapy

Disease progression with VEGFR inhibitor without prior exposure to immune checkpoint inhibitors
VEGFR Inhibitors- Axitinib, Cabozantinib, Sunitinib, Pazopanib, Lenvatinib plus everolimus

Nivolumab plus Ipilimumab if no previous exposure Ipilimumab Cabozantinib, Lenvatinib plus everolimus

Nivolumab 
Table 4 An overview of phase III clinical trials in RCC

\begin{tabular}{|c|c|c|c|}
\hline NCT name & Arm & $\begin{array}{l}\text { Primary } \\
\text { endpoint }\end{array}$ & Results \\
\hline $\begin{array}{l}\text { NCTO0903175 } \\
\text { RECORD } 3\end{array}$ & $\begin{array}{l}\text { First-line Everolimus followed by } \\
\text { second line sunitinib } \\
\text { vs } \\
\text { First line sunitinib followed by } \\
\text { second line everolimus }\end{array}$ & PFS & $\begin{array}{l}\text { Median PFS } 21.7 \text { months (mo.) (95\%Cl: 15.1-26.7) vs } 22 \text { mo. (95\%Cl16-29.8). } \\
\text { Median OS: } 22.4 \text { mo. (95\%Cl 18.6-33.3 Vs } 29.5 \text { mo. (95\% Cl:22.8-33.1) }\end{array}$ \\
\hline $\begin{array}{l}\text { NCT00720941 } \\
\text { COMPARZ }\end{array}$ & $\begin{array}{l}\text { Control arm: Sunitinib } \\
\text { Experimental arm: Pazopanib }\end{array}$ & PFS & $\begin{array}{l}\text { HR: } 1.0595 \% \mathrm{Cl}: 0.90 \text { to } 1.22 \\
\text { OS: HR: } 0.91,95 \% \text { Cl: } 0.76-1.08\end{array}$ \\
\hline $\begin{array}{l}\text { NCT00073307 } \\
\text { TARGET }\end{array}$ & $\begin{array}{l}\text { Experimental arm: Sorafenib } \\
\text { Placebo comparator: Placebo }\end{array}$ & OS & $\begin{array}{l}\text { Median PFS: } 5.5 \text { mo. vs } 2.8 \mathrm{mo} \text {. HR } 0.4495 \% \mathrm{Cl} 0.35-0.55 p<0.01 \text {. First interim analysis } \\
\text { of OS: sorafenib reduced the risk of death ( } \mathrm{HR}: 0.72 ; 95 \% \mathrm{Cl}, 0.54-0.95 P=0.02)\end{array}$ \\
\hline $\begin{array}{l}\text { NCT02231749 } \\
\text { CheckMate } \\
214\end{array}$ & $\begin{array}{l}\text { Experimental arm: Nivolumab + } \\
\text { Ipilumab } \\
\text { Active comparator: Sunitinib }\end{array}$ & $\begin{array}{l}\text { ORR, OS, } \\
\text { PFS }\end{array}$ & $\begin{array}{l}18 \text { month OS: } 75 \% \text { ( } 95 \% \mathrm{Cl}-70 \text { to } 78 \text { ) vs } 60 \% \text { ( } 95 \% \text { Cl: } 55-65) \text {; ORR: } 42 \% \text { vs } 27 \% \text {, median } \\
\text { PFS } 11.6 \text { mo. vs } 8.4 \text { mo. }\end{array}$ \\
\hline $\begin{array}{l}\text { NCT01835158 } \\
\text { Cabosun }\end{array}$ & $\begin{array}{l}\text { Arm 1: Cabozantinib } \\
\text { Arm 2: Sunitinib }\end{array}$ & PFS, OS & $\begin{array}{l}\text { Median PFS } 8.2 \text { vs } 5.6 \text { mo. adjusted HR, } 0.66 ; 95 \% \mathrm{Cl}, 0.46 \text { to } 0.95 P=0.012 \text { ORR } 33 \% \text { vs } \\
12 \%\end{array}$ \\
\hline $\begin{array}{l}\text { NCT02684006 } \\
\text { Javelin Renal } \\
101\end{array}$ & $\begin{array}{l}\text { Experimental: Avelumab plus } \\
\text { axitinib } \\
\text { Active comparator: Sunitinib }\end{array}$ & PFS, OS & $\begin{array}{l}\text { Median PFS } 13.8 \text { mo vs. } 7.2 \text { mo.HR } 0.6195 \% \text { confidence interval [CI], } 0.47 \text { to } 0.79 ; P< \\
0.001 \text {, ORR } 55.2 \% \text { vs. } 25.5 \%\end{array}$ \\
\hline $\begin{array}{l}\text { NCT02853331 } \\
\text { KEYNOTE426 }\end{array}$ & $\begin{array}{l}\text { Experimental: Pembrolizumab + } \\
\text { Axitinib } \\
\text { Active comparator: Sunitinib }\end{array}$ & PFS, OS & $\begin{array}{l}\text { Median PFS: } 15.1 \text { mo. vs. } 11.1 \mathrm{mo} \text {. HR: } 0.69 ; 95 \% \mathrm{Cl}, 0.57 \text { to } 0.84 ; P<0.001 \text { ORR: } 59.3 \% \\
(95 \% \mathrm{Cl}, 54.5 \text { to } 63.9) \text { vs. } 35.7 \% \text { ( } 95 \% \mathrm{Cl}, 31.1 \text { to } 40.4)\end{array}$ \\
\hline
\end{tabular}

PFS Progression-free survival, OS Overall survival, $H R$ Hazard ratio, ORR Overall response rate

cells. It also enhances the expression of VEGF-A, FGF2, PDGF $\beta$, and MMPs $[154,161]$.

Hypoxia also modulates ICI-mediated intrinsic resistance to therapy by selecting aggressive CSC-like RCC subpopulations of cells that are more malignant and unresponsive to antiangiogenic treatment [44]. Tumourassociated hypoxia also increases the expression of $\mathrm{P}$ glycoprotein membrane exporter (P-GP), which is responsible for cellular sequestration of many VEGF-TKIs, including sunitinib, pazopanib, and sorafenib [162].

Resistance to ICIs also occurs because hypoxia can drive immunosuppression directly and indirectly, which can affect almost all steps of classic antitumour immune cell responses. The acidic environment in the tumour, due to the rapid consumption of oxygen together with hypoxic conditions, excessively inhibits the activation, proliferation, and cytotoxicity of $\mathrm{T}$ cells. PD-1 and its interaction with PD-L1 results in suppression of the $\mathrm{T}$ cells to suppress their cytotoxic activities. In ccRCC, hypoxia via HIF- $2 \alpha$ stabilizes and upregulates PD-L1 expression [152]. HIF-1 $\alpha$, by contrast, leads to the overexpression of PD-L1 in immune cells such as myeloid-derived suppressor cells (MDSCs) and macrophages, which in turn negatively regulate cytotoxic $\mathrm{T}$ cells [163]. Along with PD-L1, hypoxia also affects other immune checkpoint inhibitors, such as the $\mathrm{V}$-domain Ig suppressor of $\mathrm{T}$ cell activation (VISTA). VISTA is overexpressed in a hypoxia-dependent manner in MDSCs and dendritic cells (DCs), leading to suppression of $\mathrm{T}$ cell multiplication and cytotoxic killing of tumour cells. Hypoxia can also indirectly lead to the production of tumour-associated macrophages (TAMs), cytotoxic T lymphocytes (CTLs), and Tregs. Hypoxic MDSCs are more immunosuppressive due to the overproduction of arginase and nitric oxide (iNOS), all of which lead to $\mathrm{T}$ cell inactivation and tumour progression [164]. CTLA-4 is also affected by hypoxia by promoting binding with its natural receptors CD80 and CD86, thereby downregulating immune responses [165].

\section{Resistance to antiangiogenic agents}

Hypervascular tumours such as RCC are dependent on increased production of growth factors including VEGF and PDGF $\beta$. In 2008, Gordon et al. suggested that deregulated stimulation of HIF- $1 \alpha$ and HIF- $2 \alpha$ genes results in the activation of different oncogenes [166]. It was noted that the subgroup with only HIF- $2 \alpha$ expression demonstrated primary resistance to the antiangiogenic drugs. Other mechanisms that are known to be associated with primary resistance include increased production of $\mathrm{B}$ cell lymphoma-2 (Bcl-2) and/or B cell lymphoma-extra-large (Bcl-XL) proteins leading to inhibition of apoptosis and overexpression of enhancer of zeste homolog $2(\mathrm{EZH} 2)$ and epigenetic modification of its promoter region $[167,168]$.

Emerging studies suggest the role of five different important processes involved in evasive resistance to antiangiogenic therapies: a) lysosomal sequestration of the drugs leading to its low bioavailability, b) tumour invasiveness and EMT, c) increased pericyte coverage of 
Table 5 Ongoing, active clinical trials in metastatic RCC involving small molecules in combination with other drugs

\begin{tabular}{|c|c|c|c|c|c|c|c|}
\hline Target & NCT number & Drug & $\begin{array}{l}\text { Combination drug/s or } \\
\text { comparator drug* }\end{array}$ & Phase & Mechanism & $\begin{array}{l}\text { Primary } \\
\text { outcome }\end{array}$ & Status \\
\hline \multirow{8}{*}{$\begin{array}{l}\text { HDAC } \\
\text { Inhibitor }\end{array}$} & NCT02619253 & Vorinostat & Pembrolizumab & । & \multirow[t]{8}{*}{ Decreased proliferation, Apoptosis } & MTD & \multirow{2}{*}{$\begin{array}{l}\text { Active no } \\
\text { recruiting }\end{array}$} \\
\hline & NCT03592472 & Abexinostat & Pazopanib & III & & PFS & \\
\hline & NCT03024437 & Entinostat & $\begin{array}{l}\text { Bevacizumab, } \\
\text { Atezolizumab }\end{array}$ & $|/| \mid$ & & Safety & Recruiting \\
\hline & NCT03552380 & Entinostat & Nivolumab, Ipilimumab & $\|$ & & Safety & Recruiting \\
\hline & NCT03501381 & Entinostat & IL-2 high dose* & ॥ & & PFS & Recruiting \\
\hline & NCT02718066 & $\begin{array}{l}\text { HBI-8000 } \\
\text { (Chidamide) }\end{array}$ & Nivolumab & $|/| \mid$ & & Safety & Recruiting \\
\hline & NCT01038778 & Entinostat & Aldeslukin & $|/| \mid$ & & $\begin{array}{l}\text { Safety, } \\
\text { dose }\end{array}$ & $\begin{array}{l}\text { Active not } \\
\text { recruiting }\end{array}$ \\
\hline & NCT02890069 & Panobinostat & PDR001,LCL16,everolimus & $|/| \mid$ & & Safety & Recruiting \\
\hline \multirow[t]{4}{*}{$\begin{array}{l}\text { Glutaminase } \\
\text { Inhibitor }\end{array}$} & NCT03163667 & $\begin{array}{l}\text { CB-839 } \\
\text { (Telaglenastat) }\end{array}$ & Everolimus & $\|$ & \multirow[t]{4}{*}{ Decreased cell proliferation and survival } & PFS & $\begin{array}{l}\text { Active not } \\
\text { recruiting }\end{array}$ \\
\hline & NCT03428217 & & Cabozantinib & $\|$ & & PFS & $\begin{array}{l}\text { Active not } \\
\text { recruiting }\end{array}$ \\
\hline & NCT02771626 & & Nivolumab & $|/| \mid$ & & $\begin{array}{l}\text { Safety, } \\
\text { tolerability } \\
\text { efficacy }\end{array}$ & $\begin{array}{l}\text { Active not } \\
\text { recruiting }\end{array}$ \\
\hline & NCT03875313 & & Talazoparib & $|/| \mid$ & & $\begin{array}{l}\text { Safety, } \\
\text { dose }\end{array}$ & Recruiting \\
\hline \multirow{4}{*}{$\begin{array}{l}\text { HIF 2a } \\
\text { Inhibitor }\end{array}$} & NCT03634540 & PT2977 & Cabozantinib & $\|$ & \multirow{4}{*}{$\begin{array}{l}\text { Impairs hypoxia, blocks transcription of } \\
\text { several angiogenesis genes }\end{array}$} & ORR & Recruiting \\
\hline & NCT03401788 & PT2977 & None & $\|$ & & ORR & $\begin{array}{l}\text { Active not } \\
\text { recruiting }\end{array}$ \\
\hline & NCT02974738 & PT2977 & None & । & & Dose & Recruiting \\
\hline & NCT02293980 & PT2385 & None & 1 & & Dose & $\begin{array}{l}\text { Active not } \\
\text { recruiting }\end{array}$ \\
\hline \multirow[t]{2}{*}{$\begin{array}{l}\text { CD73 } \\
\text { Inhibitor }\end{array}$} & NCT03549000 & NZV930 & PDR001, NIR178 & 1 & \multirow[t]{2}{*}{$\begin{array}{l}\text { Decreases tumour growth, promotes } \\
\text { CTL-mediated immune response }\end{array}$} & $\begin{array}{l}\text { Safety, } \\
\text { dose }\end{array}$ & Recruiting \\
\hline & NCT03454451 & CPI-006 & Pembrolizumab/CP-444 & । & & $\begin{array}{l}\text { Safety, } \\
\text { dose }\end{array}$ & Recruiting \\
\hline $\begin{array}{l}\text { Arginase } \\
\text { Inhibitor }\end{array}$ & NCT02903914 & CB-1158 & None & $|/| \mid$ & $\begin{array}{l}\text { Blocks Arg-1 and decreases } \\
\text { immunosuppression }\end{array}$ & Safety & Recruiting \\
\hline $\begin{array}{l}\text { Her2 } \\
\text { Inhibitor }\end{array}$ & NCT03602079 & A166 & None & $|/| \mid$ & Tumour cell apoptosis & $\begin{array}{l}\text { Safety, } \\
\text { ORR }\end{array}$ & Recruiting \\
\hline \multirow[t]{2}{*}{$\begin{array}{l}\text { CD40 } \\
\text { Agonist }\end{array}$} & NCT03329950 & CDX-1140 & CDX-301,Pembrolizumab & । & \multirow[t]{2}{*}{$\begin{array}{l}\text { Leads to activation of B cells, T cells, DC, } \\
\text { macrophages }\end{array}$} & $\begin{array}{l}\text { Safety, } \\
\text { dose }\end{array}$ & Recruiting \\
\hline & NCT03502330 & APX005M & Cabiralizumab, Nivolumab & 1 & & $\begin{array}{l}\text { Safety, } \\
\text { tolerability }\end{array}$ & Recruiting \\
\hline \multirow[t]{2}{*}{$\begin{array}{l}\text { CD137 } \\
\text { agonist }\end{array}$} & NCT03809624 & INBRX-105 & None & । & \multirow[t]{2}{*}{ T cell co-stimulation, } & $\begin{array}{l}\text { Safety, } \\
\text { dose }\end{array}$ & Recruiting \\
\hline & NCT02315066 & PF-05082566 & $\begin{array}{l}\text { PF-04518600(OX-40 } \\
\text { agonist) }\end{array}$ & । & & $\begin{array}{l}\text { Safety, } \\
\text { dose }\end{array}$ & $\begin{array}{l}\text { Active not } \\
\text { recruiting }\end{array}$ \\
\hline $\begin{array}{l}\text { STING } \\
\text { agonist }\end{array}$ & NCT03010176 & MK-1454 & Pembrolizumab & । & $\begin{array}{l}\text { Production of IFNb, enhanced cross- } \\
\text { presentation by APCs }\end{array}$ & $\begin{array}{l}\text { Safety, } \\
\text { dose }\end{array}$ & Recruiting \\
\hline $\begin{array}{l}\text { RIG-1 } \\
\text { agonist }\end{array}$ & NCT03739138 & MK-46212 & Pembrolizumab & । & $\begin{array}{l}\text { Stimulation of IFNs, enhanced anti- } \\
\text { tumour response }\end{array}$ & $\begin{array}{l}\text { Safety, } \\
\text { dose }\end{array}$ & $\begin{array}{l}\text { Active not } \\
\text { recruiting }\end{array}$ \\
\hline
\end{tabular}

MTD Maximum tolerated dose, PFS Progression-free survival, ORR Overall response rate

tumour vessels, d) bone marrow-derived proangiogenic inflammatory cell recruitment, and e) resistance through single nucleotide polymorphisms (SNPs) and microRNAs (miRNA).

\section{Lysosomal sequestration of drugs}

Sunitinib is a weak base, and its hydrophobic structure allows easy passage through the lysosomal plasma membrane. Once inside the acidic environment of the lysosomal 
structures, sunitinib becomes charged and is trapped and retained inside the lysosome. This process is known as sequestration and protects the cells from its antiangiogenic effects despite the high intracellular concentrations of the drug. Interestingly, lysosomal sequestration is a reversible process $[169,170]$. Studies on sunitinib-resistant RCC tumour cell lines have shown that sensitivity to the drug was regained and the lysosome capacity reversed after the cells were cultured without sunitinib [171].

\section{Tumour invasiveness and EMT}

Increased tumour invasiveness and initiation of malignant phenotype helps tumours to adapt to antiangiogenic therapy. In a preclinical mouse model of glioblastoma, tumour invasiveness was observed despite the downregulation of VEGF, HIF- $\alpha$, and matrix metalloproteinases (MMP-9). Induction of EMT genes activates signal cascades responsible for drug resistance, metastasis, and angiogenesis [172]. Reversal to an epithelial phenotype along with sensitivity to the antiangiogenic drugs has been demonstrated in RCC and can be considered a potential therapeutic strategy [53].

\section{Increased pericyte coverage of tumour vessels}

Pericytes are cells that are wrapped around blood vessels and express VEGF and other factors to support the proliferation and migration of endothelial cells. An increased number of pericyte-generated microvessels have been directly linked with aggressive ccRCC and resistance to therapy [173]. Pericytes are found to be critical for maintaining the tumour vasculature and increased angiogenesis in the absence of VEGF signals and therefore are perceived as potential new therapeutic targets $[174,175]$.

\section{Bone marrow-derived proangiogenic inflammatory cell recruitment}

It is widely accepted that antiangiogenic therapy causes hypoxia, which in turn stimulates proangiogenic factor production in tumours as well as recruits different bone marrow-derived cells (BMDCs). These BMDCs include CD11b-positive myeloid-derived suppressor cells (MDSC), proangiogenic tumour associated macrophages (TAM), VEGFR1-positive hemangiocytes, and circulating endothelial cells [176-179]. The proangiogenic and immunosuppressive nature of these BMDCs may be responsible for drug resistance in patients.

\section{Resistance through single nucleotide polymorphisms (SNPS) and microRNAs}

SNPs are DNA sequence variations of a single base pair that achieve a population frequency of a minimum of $1 \%$. There are SNPs located on genes that regulate the pharmacokinetics and pharmacodynamics of the VEGF-
TKIs and hence may contribute to the development of VEGF-TKI resistance [180]. SNPs in these genes can be used as predictive markers of drug resistance or efficacy [181]. CYP3A4/5 are the key enzymes in the metabolism of sunitinib. SNPs in CYP3A5 positively regulate the metabolism of sunitinib, leading to an increased metabolism of sunitinib and are often associated with increased PFS in patients [182]. By contrast, SNPs in ligand-activated nuclear receptors NR112 and NR113 negatively regulate CYP3A4 expression and are associated with decreased PFS [183]. SNPs in pharmacodynamic factors of the drug, such as VEGF-R1-3, can also lead to sunitinib resistance.

miRNAs are noncoding RNAs that play a critical role in cancer progression by silencing tumour suppressor genes. In RCC, several miRNAs have been identified. Recently, overexpression of miRNA-15b was linked to sunitinib resistance [184]. In a mi-RNA profiling study in resistant RCC cell lines, miRNA-575, miRNA-642b-3p, and miRNA-4430 were overexpressed [185].

\section{Activating bypass pathways}

Pathway bypass mechanisms confer drug resistance by recruiting alternate effector pathways to sustain oncogenic transcription and translational output. Phosphatase and tensin homolog (PTEN) is a tumour suppressor gene that negatively regulates the PI3K/Akt/mTOR pathway [186]. Mutations in PTEN lead to a continuous expression of AKT/mTOR signalling pathway. Although PTEN mutations are rare in RCC, a non-negligible number of studies have shown that PTEN is mutated and downregulated in many RCC patients [186]. Figure 5 summarizes the resistance pathways to antiangiogenic therapies.

\section{Resistance to immune checkpoint inhibitors}

For the immune system to destroy tumour cells and for the immune checkpoint inhibitors to work efficiently, three important steps of the cancer-immunity cycle have to occur: 1) antigen presentation and T cell activation, 2) $\mathrm{T}$ cell trafficking and tumour infiltration, and 3) T cell killing activity within the TME. Immune evasion can occur at any of the above steps and can lead to primary or adaptive resistance in patients receiving immunotherapy.

Lack of T cell priming and impaired antigen presentation The inability of the immune system to elicit a response against tumour antigens can result from the lack of tumour antigens that can be recognised as foreign or the lack of sufficient antigen presentation by the antigenpresenting cells [187]. The primary reason for low immunogenicity in patients may result from a low mutational burden causing in inadequate tumour-associated antigens presentation by $\mathrm{DC}$ that fails to initiate a $\mathrm{CD} 8^{+}$ 


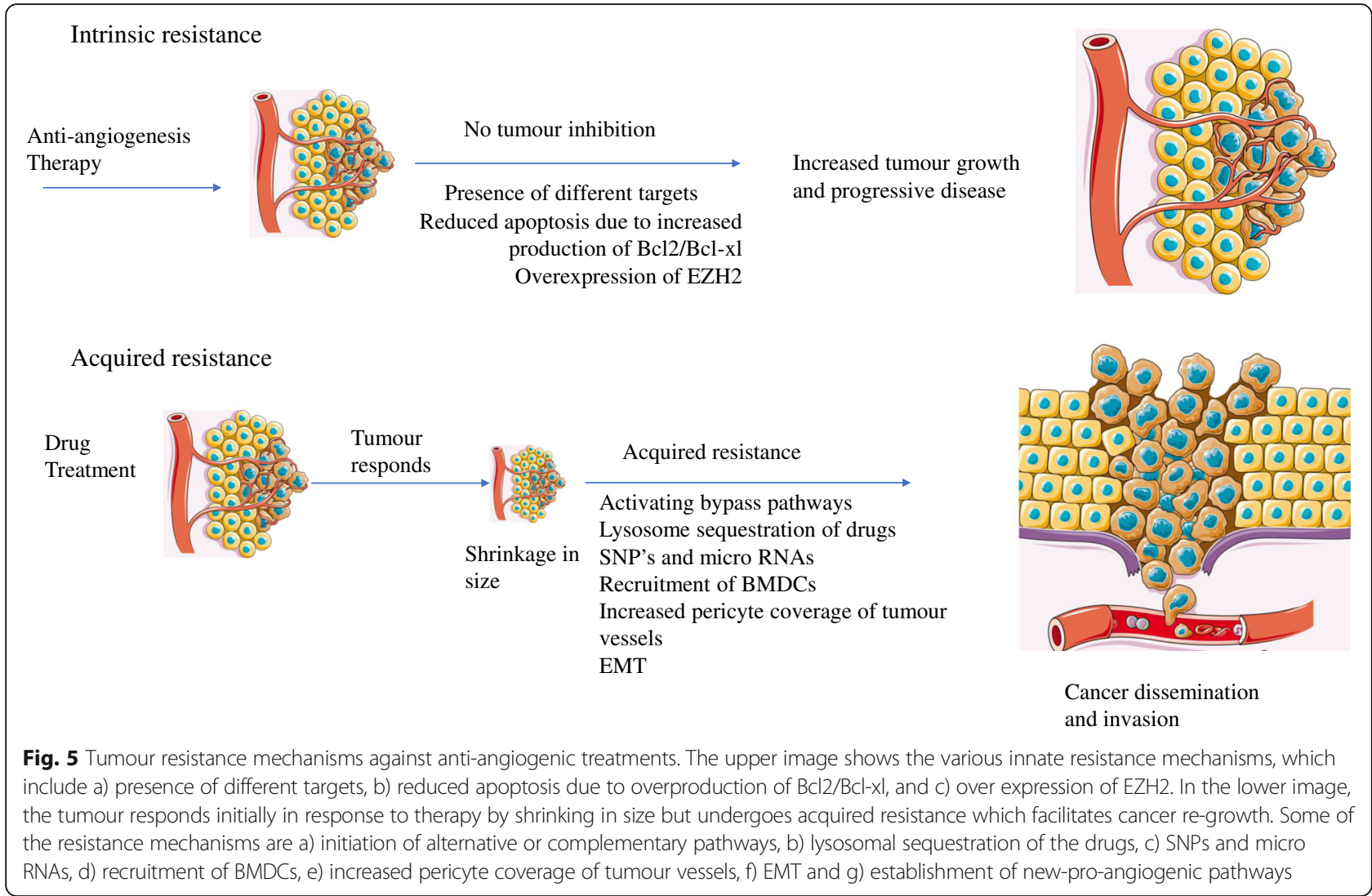

response in the patients. RCC has a relatively low mutational burden [188], and this can render RCC tumours non-responsive to ICI treatments. Lack of antigen presentation can also be attributed to mutations that affect the structure of major histocompatibility complex $(\mathrm{MHC})$, proteasome, and transporters associated with antigen processing.

Loss of beta-2-microglobulin can lead to impaired MHC class I expression. This loss causes a subsequent decrease in antigen presentation via MHC class I, leading to reduced detection of the tumour cells by $\mathrm{CD} 8^{+}$ cells and rendering tumours less sensitive to $\mathrm{T}$ cell infiltration. Antigen presentation and recognition with the help of MHC can also be affected by epigenetic changes such as histone acetylation and hypermethylation.

Functional antigen presentation by mature DCs is an absolute requirement for $\mathrm{T}$ cell activation. Mature DCs have improved capacity to stimulate $\mathrm{T}$ cells through high expressions of cytokines and expression of MHC class I/II and a variety of costimulatory molecules, such as CD80, CD86, and CD40, which are key to the processes of $\mathrm{T}$ cell priming [189]. Immune checkpoint inhibitors rely heavily on the cross-presentation of tumour antigens, and the process is hampered when the DCs present in the TME do not function effectively. Hypoxia increases lactate levels, and a decrease in $\mathrm{pH}$ can suppress $\mathrm{DC}$ maturation and function [190]. STAT3 is also known to promote crosstalk between the tumour and immune cells and induces S100 calcium binding protein A9, which suppresses the maturation of DCs by blocking their responsiveness to local danger signals. STAT3 is also responsible for the induction of immunosuppressive factors such as IL10, regulatory $\mathrm{T}$ cells (Treg), and transforming growth factor beta (TGF- $\beta$ ), all of which may impair the maturation and normal function of DCs [190, 191].

\section{Decreased T cell activity in the tumour microenvironment (TME)}

A recent RCC study showed that TME has an impact on the way cancer progresses and resists ICI therapies [192]. Loss of function mutations of Janus kinase $1 / 2$ (JAK1/JAK2), which is responsible for the antitumor activity of IFN- $\gamma$, can lead to tumours being refractory to immune checkpoint inhibitors. The interaction of tumour cells with immune cells can have multiple outcomes. Certain interactions can impair the antitumour activity of the ICIs despite adequate antigen presentation and $\mathrm{T}$ cell infiltration. Either Tregs inhibit $\mathrm{T}$ cell activity directly via cell-to-cell contact or indirectly by secreting inhibitory molecules such as IL-10, IL-35, and TGF- $\beta$, all of which can suppress CD8 $+\mathrm{T}$ cell infiltration into tumours and its associated functions [191, 193]. MDSCs 
a

Primary resistance

- Lack of tumour antigens

- Lack of antigen presentation

- Immature and non functional DC

Acquired resistance

- Impaired MHC Class I expression

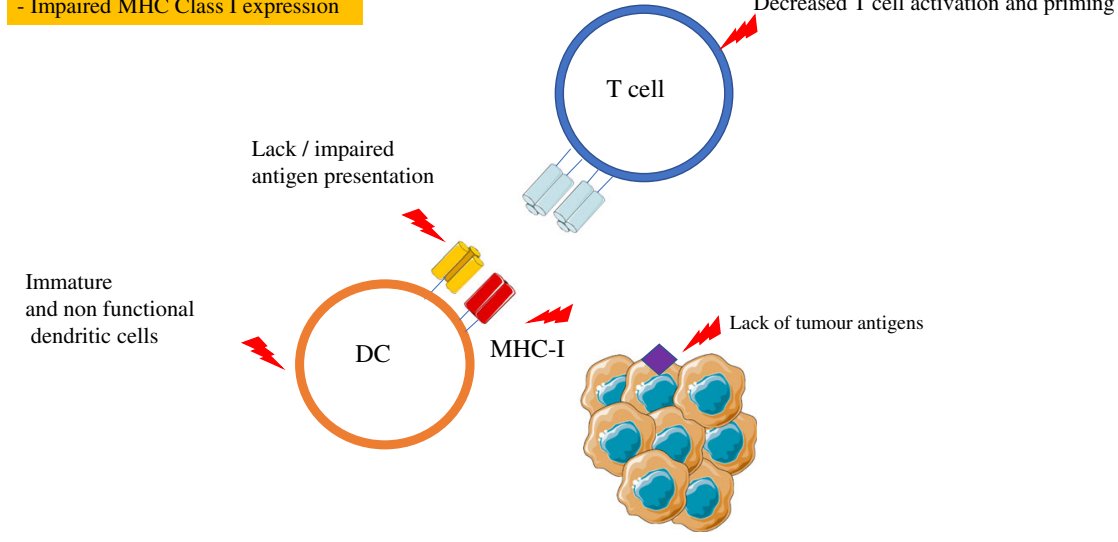

\section{b}

Primary resistance

- Increased PD-L1 production

- Upregulation of T regs

Mutation leading to loss of function

Induction of IDO1

Acquired resistance

Acquired resistance

Mutation of JAK $1 / 2$
Increased Immune checkpoint markers

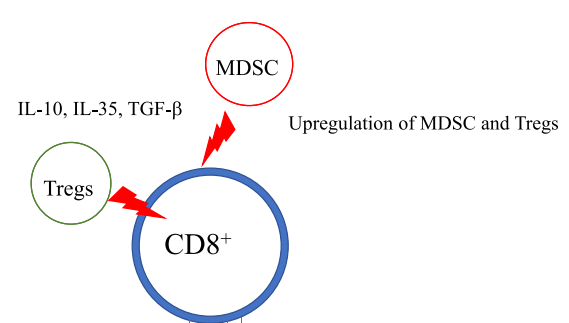

Mutation in JAK1/2

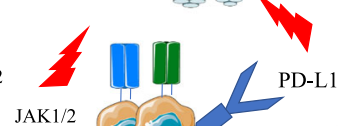

Increased immune checkpoint markers

IDO1 - Induction of IDO1

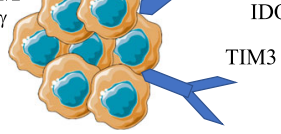

c
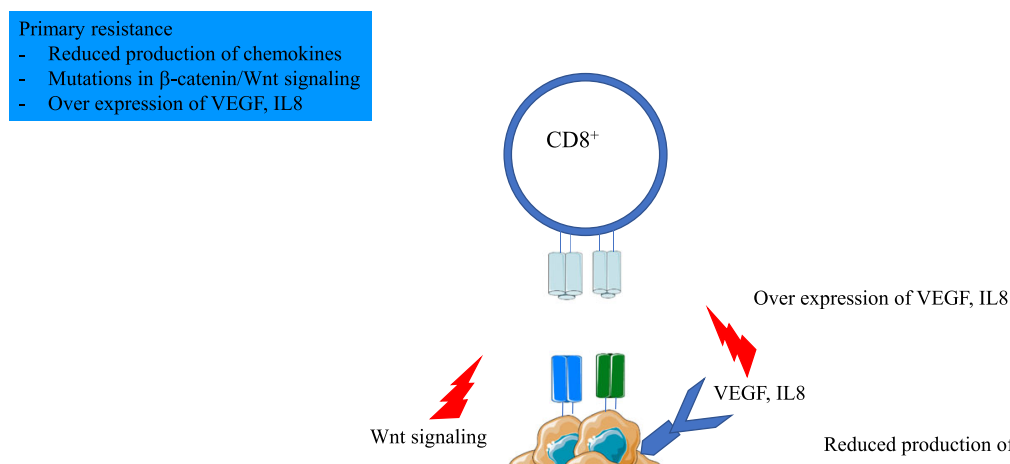

Reduced production of chemokines

Mutations in $\beta$-catenin/Wnt signaling

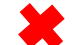

Fig. 6 (See legend on next page.) 
(See figure on previous page.)

Fig. 6 Resistance to ICl therapy. Various putative or acquired immune escape mechanisms can result in tumour evading the immune checkpoint inhibitor therapy. These include; a) Lack of T cell priming through impaired antigen presentation via inadequate DC maturation or through appropriate MHC1 expression; b) decreased T cell activity in the tumour microenvironment through increased infiltration of Tregs, expression of T cell suppressive molecules on tumour cells such as IDO, PD-L1, or mutational changes in JAK2 pathway, loss of tumour suppressor genes such as PTEN or increased expression of T cell exhaustion markers such as TIM-3, PD-1, etc.; c) lack of T cell infiltration in the tumour microenvironment due to enhanced LDH accumulation, low expression of T cell migratory chemokines, increased expression of tumour suppressive cytokines such as TGF- $\beta$, IL-6, IL-8, etc.

can suppress T cell activity by a series of various actions, including production of ROS, arginase, IL-10, nitrosylation of chemokines, and depleting nutrients such as cysteine and tryptophan, which are vital nutrients for $\mathrm{T}$ cells [194]. Studies have shown that depleting or impairing Tregs or MDSCs restores the anticancer activity of ICIs $[191,195,196]$.

Upregulation of immune checkpoint markers has been linked to decreased $\mathrm{T}$ cell killing in TME. Increased expression of PD-L1 can lead to decreased functioning of cytotoxic $\mathrm{T}$ cells and apoptosis, leading to tumour progression [197]. Indoleamine 2,3-dioxygenase (IDO1) and lymphocyte activation gene 3 (LAG3) can lead to negative regulation of $\mathrm{T}$ cells by activation of MDSCs in a Tregdependent process and by leading to a state of immune exhaustion in the TME, respectively $[198,199]$. Tumour cells expressing PD-L1 and T cell immunoglobulin mucin (TIM-3) can downregulate T cell functions [200].

\section{Absence of $\mathrm{T}$ cells in the tumour microenvironment}

Mutations within the tumour can result in the inhibition of $\mathrm{T}$ cell recruitment to the tumour microenvironment. Mutations that lead to an increase of $\beta$-catenin/Wnt signalling in tumours ultimately leads to reduced $\mathrm{CD} 8^{+} \mathrm{T}$ cells and $\mathrm{CD} 103^{+}$infiltration in the tumour [201]. Expression of C$\mathrm{X}-\mathrm{C}$ motif chemokine receptor (CXCR3) is important for $\mathrm{T}$ cell trafficking and function [202]. Epigenetic alterations, including histone modification and DNA methylation in tumour cells, repress chemokines, thereby allowing tumour cells to evade $\mathrm{T}$ cell trafficking [203]. Other mutations in the MAPK pathway, leading to overexpression of VEGF and IL-8 have also been detected. These cytokines inhibit T cell recruitment in the tumour. Mutation of the tumour suppressor PTEN gene is also linked to decreased $\mathrm{CD} 8^{+} \mathrm{T}$ cell infiltration owing to the inhibitory activity of overexpressed VEGF. Figure 6 summarizes some mechanisms of ICI resistance in RCC patients.

\section{Composition of gut microbiome}

Current studies have revealed the potential role of the gut microbiome in modulating primary ICI resistance in RCC [204, 205]. The composition of the gut microbiome may affect the antitumour activity of the ICIs [152]. Greater microbial diversity correlates with improved response to ICIs [152]. Antibiotics can greatly alter gut biodiversity. A study tested the effect of antibiotics on patients with RCC who had previously received PD-1/PD-L1mAb. A shorter PFS and OS was observed in the antibiotic-treated patient group. Further, the presence of Akkermansia muciniphila bacterial species in the gut was associated with excellent clinical outcomes in RCC patients. The tumour suppressor activity may be partly due to the production of the short-chain fatty acids, propionate and acetate, by the commensal bacteria. Propionate is the ligand of G-protein-coupled receptor 41, which mediates tumour cell apoptosis [204]. Another study showed that antibiotic therapy was associated with reduced clinical outcomes with ICIs in RCC and suggested modulation of antibiotic therapyrelated dysbiosis and gut microbiota as a strategy to improve the clinical benefits of ICI treatment [205]. In summary, multiple resistance mechanisms could be at play in mRCC patients treated with VEGF inhibitors and ICIs as monotherapy.

\section{Vaccines and viruses}

Several vaccines that target tumour-specific antigens called neo-antigens are now under development for RCC. The trials undertaking vaccines are either as monotherapy or in conjunction with immune checkpoint inhibitors. Currently, three types of therapeutic cancer vaccines are being researched in different cancers: autologous and allogenic vaccines, DC vaccines and protein/peptide-based, genetic vaccines (DNA/RNA) [206]. A phase I study of recombinant adenovirus encoding GMCSF-CAIX fusion gene transduced autologous dendritic cells in RCC showed encouraging results with regards to its safety in patients. Oncolytic viruses are promising alternatives that specifically target cancer cells, infecting and replicating in them. The viruses are modified to use cancer cell machinery to induce transgene expression, resulting in the apoptosis of tumour cells. All the clinical trials using vaccines and viruses in RCC are described in detail in Table 6.

\section{Novel therapeutic strategies currently being tested for mRCC}

Research in RCC is continuously evolving, and more understanding of the molecular characteristics and 
Table 6 Summary of active clinical trials applying vaccinal and oncolytic virus strategies

\begin{tabular}{|c|c|c|c|c|c|c|c|}
\hline NCT number & $\begin{array}{l}\text { Agent/ } \\
\text { Drug }\end{array}$ & Vaccine type & $\begin{array}{l}\text { Combination } \\
\text { drug/s }\end{array}$ & Phase & Mechanism & $\begin{array}{l}\text { Primary } \\
\text { outcome }\end{array}$ & Status \\
\hline NCT02950766 & NeoVax & Peptide-based & Ipilimumab & I & Personalised neoantigen vaccine & Safety, dose & Recruiting \\
\hline NCT03715985 & $\begin{array}{l}\text { EVAX-01- } \\
\text { CAF09b }\end{array}$ & Peptide-based & $\begin{array}{l}\text { anti-PD-1, anti-PD- } \\
\text { L1 }\end{array}$ & । & & $\begin{array}{l}\text { Safety, } \\
\text { efficacy }\end{array}$ & Recruiting \\
\hline NCT00458536 & $\begin{array}{l}\text { DC tumour } \\
\text { fusion }\end{array}$ & Dendritic cell & GM-CSF & $|/| \mid$ & Improving antigen presentation & Safety & $\begin{array}{l}\text { Active not } \\
\text { recruiting }\end{array}$ \\
\hline NCT03548467 & VB10.NEO & DNA Plasmid & Bempegaldesleukin & $|/| \mid$ & $\begin{array}{l}\text { Improved immune response elicited by } \\
\mathrm{CD} 4^{+} \text {and } \mathrm{CD} 8^{+} \mathrm{T} \text { cells }\end{array}$ & Safety & Recruiting \\
\hline NCT03633110 & GEN-009 & Autologous & $\begin{array}{l}\text { Nivolumab/ } \\
\text { Pembrolizumab }\end{array}$ & $|/| \mid$ & Elicit $\mathrm{CD}^{+} \mathrm{T}$ cell response & Safety & $\begin{array}{l}\text { Active not } \\
\text { recruiting }\end{array}$ \\
\hline NCT03294083 & Pexa-Vec & $\begin{array}{l}\text { Oncolytic } \\
\text { vaccinia virus }\end{array}$ & REGN2819 & । & $\begin{array}{l}\text { Stimulate immune response, replicates in } \\
\text { and lyses tumour cells }\end{array}$ & $\begin{array}{l}\text { ORR, safety, } \\
\text { dose }\end{array}$ & Recruiting \\
\hline
\end{tabular}

resistance mechanisms in RCC tumours is being discovered. Clinical trials involving novel strategies are being carried out with the primary objective of improving the clinical outcome and expanding treatment options for patients with mRCC.

\section{Novel therapies targeting tyrosine kinases under investigation}

Preliminary studies on savolitinib, also called volitinib, a highly selective MET inhibitor, showed anti-tumour activity in pRCC [207]. pRCC is a MET-driven tumour and currently has no specifically approved treatment. SAVOIR, a randomised phase III trial, is evaluating the efficacy and safety of savolitinib compared with sunitinib (NCT03091192). The role of Activin receptor-like kinase (ALK) is well known in modulating angiogenesis. Dalantercept, a known ALK inhibitor, showed promising results in a phase I trial; however, it did not appear to improve the treatment-related outcomes in RCC patients despite being well tolerated [208]. Crizotinib, an ALK and MET inhibitor, was well tolerated in advanced metastatic pRCC and achieved long-lasting disease control in a cross-tumoural phase II trial, CREATE. The preliminary results were published in 2017 , and the study is expected to be completed in 2020 (NCT01524926). In a phase II trial study, savolitinib is being compared to cabozantinib S-malate, crizotinib, and sunitinib malate in metastatic pRCC (NCT02761057). A VEGFR and PDGFR inhibitor, vorolanib in combination with everolimus, is being evaluated in a phase II/III trial, CONCEPT study (NCT03095040). Furthermore, ibrutinib, a Bruton tyrosine kinase (BTK) inhibitor, showed a decrease of the renal mass in a case study involving a 66-year-old male referred for a left renal mass along with newly diagnosed CLL. Currently, there are two-phase I/II clinical trials investigating the use of ibrutinib in mRCC (NCT02899078 and NCT02599324). Ibrutinib shows its effect through inhibition of IL2-inducible $\mathrm{T}$ cell kinase, leading to a shift in the ratio between $\mathrm{T}$ helper 1 and $\mathrm{T}$ helper $2 \mathrm{~T}$ cells, thereby enhancing antitumour activity. They are also known to inhibit PD-1 or CTLA-4 [209].

\section{Novel immunomodulatory approaches}

Modulation of these immune responses remains a very fascinating therapeutic approach in mRCC. Most of the focus has remained on PD-1/PD-L1 and CTLA-4. However, few other immunomodulatory pathways and molecules are being exploited to improve the overall response of mRCC patients. Some recent strategies for ICI treatment in RCC are described below.

LAG-3 exerts immune homeostasis by suppressing $\mathrm{T}$ cell functions and is normally expressed by exhausted tumour-infiltrating lymphocytes. It interacts in synergy with PD-1 to inhibit immune responses. Currently, few trials are investigating the action of LAG-3. LAG525, an anti-LAG-3 antibody, is being used as a single therapy and in combination with PDR001 and anti-PD1 (NCT02460224). A phase II trial FRACTION-RCC is investigating relatlimab, another anti-LAG-3 antibody in combination with nivolumab (NCT02996110). A phase I study, DUET-4, which evaluates $\mathrm{XmAb}^{\circ} 22,841$, a bispecific antibody targeting CTLA-4 and LAG-3, is being undertaken and is expected to be completed in 2027 (NCT03849469).

IDO-1 is an immunomodulatory enzyme that converts tryptophan to kynurenine. It suppresses T and NK cells and promotes the proliferation of Tregs and MDSCs. The overexpression of IDO-1 in tumours leads to the depletion of tryptophan and increased production of kynurenine in the TME. These changes result in ineffective $\mathrm{T}$ effector cell activity and an increased immunosuppressive TME, allowing the tumour cells to escape immune surveillance. Epacadostat and Linrodostat (BMS-986205) are the two IDO-1 inhibitors currently under investigation in RCC under separate clinical trials. NCT03260894, NCT02178722, and NCT03277352 are all in combination with pembrolizumab and other drugs. NCT02996110 is in combination with nivolumab. 
Hypoxia and cellular damage in cancer lead to the accumulation of adenosine in TME. Extracellular adenosine, along with its G-protein-coupled adenosine receptors, mediates immunosuppressive activity through various mechanisms, such as stabilizing Tregs, rendering CD8 T cells ineffective, downregulating IL2, and inhibiting TCR signalling. Some clinical trials are underway investigating adenosine receptor inhibitors alone or in combination with other drugs: AB928 (NCT03629756) and CPI-444 (NCT03454451, NCT02655822).

$\mathrm{V}$-domain Ig suppressor of $\mathrm{T}$ cell activation (VIST A) impedes $\mathrm{T}$ cell activity, and blocking it has been shown to improve $\mathrm{T}$ cell activity and inhibit $\mathrm{T}$ cell immunosuppressive functions. CA-170, a small molecule VISTA inhibitor that also targets PD-L1/2, is being investigated in a phase 1 trial in RCC and other advanced solid tumours. This trial aims to assess the dose-limiting toxicity in the first treatment cycle (NCT02182875).

Co-stimulatory immune checkpoint inhibitors are also in ongoing trials in mRCC. Agonistic antibody of glucocorticoid-induced TNF receptor (GITR) and OX40 (CD137) and co-stimulatory receptors of TNF superfamily are under evaluation in various clinical trials. Expression of GITR enhances antitumour activity by decreased immunosuppression and enhanced co-stimulatory function of $\mathrm{CD}^{+} \mathrm{T}$ cells, whereas OX40 enhances the proliferation and survival of $\mathrm{CD}^{+}$and $\mathrm{CD}^{+} \mathrm{T}$ cells. INCA GN0186 is an agonistic anti-GITR antibody, while PF04518600 is an agonistic antibody of OX40. The compounds are being investigated alone (NCT02697591 and NCT02315066, respectively) or in combination with other already approved drugs, such as nivolumab + ipilimumab (NCT03126110) and axitinib (NCT03092856).

Chimeric-antigen receptor (CAR) $\mathrm{T}$ cells are genetically engineered $\mathrm{T}$ cells that have recently entered the therapeutic testing horizons of RCC. The T cells are tailor-made to have antigen-binding receptors along with signalling domains needed for $\mathrm{T}$ cell activity. CAR-T cells have shown promising results in haematological malignancies, but the same has yet to be obtained in solid tumours like RCC, especially because of the immunosuppressive TME prevalent in these tumours. However, in a recent pre-clinical study, CAIX-specific CAR$\mathrm{T}$ cells in combination with sunitinib showed synergistic effects against mRCC models [210]. CAR-T cells are currently being tested targeting a plethora of antigens, namely CD70 (NCT02830724), c-MET (NCT03638206), VEGFR2 (NCT01218867), ROR2, and AXL (NCT03393936). There are now second-generation CAR-T cells that have additional co-stimulatory receptors (CD28 and/or 4-1BB).

\section{Combination therapy (target therapy and immunotherapy)}

Pathways affecting angiogenesis and immune responses are intertwined and can positively or negatively affect each other. Of no surprise is the proven success of combining ICIs and target therapy drugs as an emerging approach in several clinical trials. The current ongoing phase III trials combining immune checkpoint inhibitors and target therapy are detailed in Table 7.

\section{Other small molecule drugs}

Currently, immune checkpoint inhibitors are also being tested in combination with many other small molecules. In particular, a few different histone deacetylase (HDAC) inhibitors are being tested. HDAC1 and HDAC2 are important for the growth and survival of RCC cells. Inhibition of HDACs can lead to apoptosis and reduction of proliferation of the RCC cells [211]. HDAC inhibitors entinostat and panobinostat are currently being investigated in combination with immune checkpoint inhibitors nivolumab plus ipilimumab and PD-1 inhibitor PDR001 respectively. A phase III clinical trial RENAVIV is currently investigating Abexinostat, a deacetylase

Table 7 Active Phase III clinical trials with novel therapeutic drugs in mRCC

\begin{tabular}{|c|c|c|}
\hline NCT name & Drug/procedure combinations & Primary outcome \\
\hline $\begin{array}{l}\text { NCT03055013 } \\
\text { PROSPER }\end{array}$ & Nephrectomy vs. Perioperative Nivolumab & RFS \\
\hline $\begin{array}{l}\text { NCT03592472 } \\
\text { RENAVIV }\end{array}$ & Pazopanib + Placebo vs. Pazopanib + Abexinostat & PFS \\
\hline NCT03260894 & Sunitinib/Pazopanib vs. Pembrolizumab + Epacadostat & ORR \\
\hline $\begin{array}{l}\text { NCT03288532 } \\
\text { RAMPART }\end{array}$ & Durvalumab vs Durvalumab + Tremelimumab & DFS \\
\hline NCT03142334 & Pembrolizumab (Adjuvant setting) & DFS \\
\hline $\begin{array}{l}\text { NCT03138512 } \\
\text { CheckMate } 914\end{array}$ & Nivolumab + Ipilimumab (Adjuvant setting) & DFS \\
\hline NCT03091192 & Savolotinib vs. Sunitinib & PFS \\
\hline $\begin{array}{l}\text { NCT03024996 } \\
\text { IMmotion } 010\end{array}$ & Atezolizumab (Adjuvant setting) & DFS \\
\hline
\end{tabular}


inhibitor, along with pazopanib as a first-line drug for mRCC and is expected to be finished by 2022 (NCT03592472).

\section{Future direction and conclusion}

The number of published reviews on RCC in the literature are enormous. However, most of them focus on specific aspects of RCC, such as the biology, directed towards specific molecular mechanisms for example hypoxia, EMT/CSC, or emphasize on the failure of past treatments and the pros and cons of present treatment methods. There is, however, a lack in the literature of studies that consolidate findings on basic biological changes leading to RCC development, which can be interrogated clinically to identify drug targets forming the basis of clinical trials and subsequent treatments. In this review, we have tried to address these issues, attempted to provide a holistic view on the fundamental biological changes regulating RCC development, progression and combined that information with the basis of therapy resistance, development of clinical trials and subsequent treatments. Our other rationale for this review was to consolidate the information in the literature about the molecular and biological changes leading to RCC progression and justify that with the data generated in our laboratory on patient samples. In addition, effort was made to update the readers on the mechanistics and pros and cons of current treatment protocols, information on current clinical trials, and the conceptualisation of the evolving RCC field in relation to precision medicine.

With the recent understanding of RCC pathogenesis, many new therapeutic strategies are being developed, and a few of them including immunotherapies targeting programmed cell death (PD-1)/programmed deathligand 1 (PD-L1), as single agents or in combination with anti-CTLA-4 monoclonal antibodies or a multitarget VEGF-TKIs have gained FDA approval as treatment regimens in clinical settings. Such progress has improved the overall survival of mRCC patients. However, the overall response rates achieved through immune therapy and combination treatments still remains as low as $\sim 20-30 \%$ and is associated with substantial toxicity profiles, which needs improvement to achieve better treatment results [212-214]. One approach to achieve higher response rates in patients would be to target multiple checkpoint inhibitors besides the commonly known ones in combination with TKIs. However, this may result in greater toxicity $[142,215]$. Hence, there is an urgent need to identify alternative combination strategies, which would improve clinical outcomes in patients without the significant risk of toxicities.

As discussed above, HIF-associated hypoxia is the hallmark of RCC initiation and progression. Hypoxia not only induces genomic instability but also accelerates EMT/metastases, defects in apoptosis/autophagy, induction of CSCs and resistance to therapies. Hypoxia generates an inflamed pro-angiogenic, immunosuppressive TME, which boosts the malignant cells to undergo metastatic progression and therapy resistance. Hence, specific targeting of hypoxia using hypoxia-targeted drugs may achieve better results in RCC treatment. In that context, trials using hypoxia targeting signalling molecules are currently being exploited in cancer therapy [216, 217].

Further to that, from the hypoxia standpoint, caution should be taken in using maximum tolerated dose (MTD) of traditional anti-angiogenic drugs as it may successfully shrink the tumours but induce secondary hypoxia, accelerating hypoxia-associated tumourigenesis and compromising anti-tumour immunity by priming immunosuppressive cells infiltration in tumours [218, 219]. In that context, an elevated concentration and extended period of anti-VEGF therapy treatment was associated with decreased oxygen supply associated with hypoxia in tumours [220, 221]. Nevertheless, a proper use and timing of the anti-angiogenic drugs can revert the hypoxia process by normalizing the tumour vasculature by intervening with oxygen delivery [222, 223]. Hence, dosage of anti-angiogenic drugs and the frequency of its administration is key for successful antiangiogenic treatment. A lower concentration of antiangiogenic drugs, as low as one-quarter of the conventional dose, has shown sustained vascular normalization in preclinical models [220, 224]. Clinical studies in patients with glioblastoma and breast cancer have confirmed these results, by showing that a decreased dose of anti-VEGF $(<3.6 \mathrm{mg} / \mathrm{kg} /$ week $)$ after cytoreductive surgery provides improved survival compared to high dose of anti-VEGF at $5 \mathrm{mg} / \mathrm{kg} /$ week [225, 226]. In addition, combination of anti-angiogenesis and anti-immune therapy studied in pre-clinical models as well as in clinical settings have shown immense potential as future therapeutics [227-229]. Hence, the treatment landscape of mRCC holds promise by optimising low doses of combination of anti-angiogenic and immune-directed therapies essential to tackle the complex hypoxia-oriented TME.

Despite the above developments, a wide research gap still exists in understanding individual patient tumour biology and alignment of that with the choice of appropriate drug for treatment. Unlike most solid tumours, there are currently no biomarker driven drug approvals in RCC [230]. Immune and other targeted therapies are prescribed to RCC patients depending on specific risk scores [231]. In addition, no reliable biomarker exists to indicate which group of patients will benefit from specific immune therapies [232]. Even though cytoreductive nephrectomy is common in RCC patients, $\sim 30 \%$ of 
metastasis-free patients develop recurrent cancer after cytoreductive surgery within a short time frame. This suggests that there is a need for the use of adjuvant therapy, which will keep the microscopic tumour under check after cytoreductive surgery. In the adjuvant settings, TKIs on their own have not proven satisfactory, suggesting a change of treatment paradigm, which relies on immunotherapy with or without TKIs in moderatehigh risk patients. However, in that scenario establishment of valid predictors for immunotherapy treatment response is essential [232]. As a single biomarker for patient selection has not proven successful, a panel of biomarkers based on components such as PD-LI expression in tumours, degree of tumour infiltrated T cells, expression of exhaustion markers on lymphocytes, tumour mutational burden, etc. may provide better prediction of patient's response to immune and related therapies. Furthermore, a more improved understanding of the biology of different subtypes of RCC based on the data collected by large public datasets such as TCGA, TRACERx Renal, etc. may provide identification of biomarker-oriented approaches necessary for the stratification of patients for specific treatment modalities [230]. This may guide clinicians to tailor best-personalized treatment to patients.

\begin{abstract}
Abbreviations
VEGF-TKI: Tyrosine kinase inhibitors; RCC: Renal cell carcinoma; ICl: Immune checkpoint inhibitors; ccRCC: Clear cell renal cell carcinoma; pRCC: Papillary RCC; chRCC: Chromophobe RCC; VHL: von-Hippel-Lindau gene; pVHL: vonHippel Lindau protein; HIF: Hypoxia inducible factor proteins; LDH: Lactate dehydrogenase; PDK: Pyruvate dehydrogenase kinase; GLUT1: Glucose transporter 1; HK: Hexokinase; EGFR: Epidermal growth factor receptor; p53: Tumour protein 53; mTOR: Mammalian target of rapamycin; EMT: Epithelial-mesenchymal transition; OS: Overall survival; PFS: Progressionfree survival; IL6: Interleukin 6; IL8: Interleukin 8; TNF-a: Tumour necrosis factor a; miRNA: Micro-RNA; CSC: Cancer stem cells; TGF $\beta$ : Transforming growth factor $\beta ;$ CD: Cluster of differentiation; mRCC: Metastatic RCC; FDA: Food and Drug Administration; IFN a: Interferon a; VEGF: Vascular endothelial growth factor; VEGFR: Vascular endothelial growth factor receptor; mPFS: Median PFS; ORR: Overall response rate; IMDC: International Metastatic RCC Database; AE: Adverse effects; PD-1: Programmed cell death protein - 1; PD-L1: Programmed cell death ligand - 1; TME: Tissue microenvironment; MMP: Matrix metalloproteinases; BMDC: Bone marrowderived cells; TAM: Tumour associated macrophages; SNP: Single nucleotide polymorphisms; PTEN: Phosphatase and tensin homolog; STAT3: Signal transducer and activator of transcription 3; MDSC: Myeloid-derived suppressor cells; IDO1: Indoleamine 2,3-dioxygenase; LAG3: Lymphocyte activation gene 3; TIM3: T-cell immunoglobulin mucin
\end{abstract}

\section{Acknowledgements}

This work was made possible through funds from John Turner Cancer Research Funds and the Victorian State Government Operational Infrastructure Support to Hudson Institute of Medical Research.

\section{Authors' contributions}

RS undertook the literature review, was involved with the conception of the idea and wrote the article. EK contributed to the literature search and editing of the manuscript. PP, GK and MM read and edited the final version of the manuscript. NA was involved with conceiving the idea, writing and editing the manuscript. All authors have read and approved the manuscript.

\section{Funding}

This work was supported by John Turner Cancer Research Funds to Fiona Elsey Cancer Research Institute, Ballarat, Australia. RS is the recipient of a
John Turner Cancer Research PhD scholarship, Fiona Elsey Cancer Research Institute and Federation University Australia, Ballarat, Australia.

\section{Availability of data and materials}

The datasets presented in the review are not publicly available as it is part of a PhD thesis, which is in progress. However, if required the data can be obtained from the corresponding author on a reasonable request.

\section{Declarations}

Ethics approval and consent to participate and publish

The human tissue samples used in this project are from primary tumour surgical specimens donated with consent from patients under Human Ethics application (HREC/11/BHSSJOG/24) approved for Fiona Elsey Cancer Research Tissue Bank by Ballarat Health Services.

\section{Consent for publication}

Patients donating the human tissue samples in this project consented for participation in the study under Human Ethics application (HREC/11/ BHSSJOG/24) approved by Ballarat Health Services, Ballarat, Australia.

\section{Competing interests}

The authors declare no competing interests.

\section{Author details}

${ }^{1}$ Fiona Elsey Cancer Research Institute, Ballarat, Victoria 3350, Australia. ${ }^{2}$ Federation University Australia, Ballarat, Victoria 3350, Australia. ${ }^{3}$ The Hudson Institute of Medical Research, Clayton, Victoria 3168, Australia. ${ }^{4}$ Department of Obstetrics and Gynaecology, University of Melbourne, Melbourne, Victoria 3052, Australia.

Received: 6 January 2021 Accepted: 25 April 2021

Published online: 07 June 2021

\section{References}

1. Bray F, Ferlay J, Soerjomataram I, Siegel RL, Torre LA, Jemal A. Global cancer statistics 2018: GLOBOCAN estimates of incidence and mortality worldwide for 36 cancers in 185 countries. CA Cancer J Clin. 2018;68(6):394-424.

2. Koul H, Huh J-S, Rove KO, Crompton L, Koul S, Meacham RB, et al. Molecular aspects of renal cell carcinoma: a review. Am J Cancer Res. 2011;1(2):240-54.

3. Delahunt B, Srigley JR, Egevad L, Montironi R. International Society of Urological Pathology Grading and Other Prognostic Factors for renal Neoplasia. Eur Urol. 2014;66(5):795-8.

4. Mlcochova H, Machackova T, Rabien A, Radova L, Fabian P, lliev R, et al. Epithelial-mesenchymal transition-associated microRNA/mRNA signature is linked to metastasis and prognosis in clear-cell renal cell carcinoma. Sci Rep. 2016;6(1):31852.

5. Bhat $\mathrm{S}$. Role of surgery in advanced/metastatic renal cell carcinoma. Indian J Urol. 2010;26(2):167-76.

6. Chondroma DMa. In: Popa GT, editor. Atlas of pathology. 3rd ed. lasi: University of Medicine and Pharmacy; 2010

7. Valenca LB, Hirsch MS, Choueiri TK, Harshman LC. Non-clear cell renal cell carcinoma, part 1: histology. Clin Adv Hematol Oncol. 2015;13(5):308-13.

8. Varshney N, Kebede AA, Owusu-Dapaah H, Lather J, Kaushik M, Bhullar JS. A review of Von Hippel-Lindau syndrome. J Kidney Cancer VHL. 2017;4(3):20-9.

9. Kim E, Zschiedrich S. Renal cell carcinoma in von Hippel-Lindau disease-from tumor genetics to novel therapeutic strategies. Front Pediatr. 2018;6:16.

10. Razafinjatovo C, Bihr S, Mischo A, Vogl U, Schmidinger M, Moch H, et al. Characterization of VHL missense mutations in sporadic clear cell renal cell carcinoma: hotspots, affected binding domains, functional impact on $\mathrm{pVHL}$ and therapeutic relevance. BMC Cancer. 2016;16:638.

11. Bertout JA, Patel SA, Simon MC. The impact of $\mathrm{O} 2$ availability on human cancer. Nat Rev Cancer. 2008;8(12):967-75.

12. Imtiyaz HZ. SMC. Hypoxia-inducible factors as essential regulators of inflammation. In: Simon M, editor. Diverse effects of hypoxia on tumor progression current topics in microbiology and immunology, vol. 345. Berlin, Heidelberg: Springer; 2010.

13. Semenza GL. Targeting HIF-1 for cancer therapy. Nat Rev Cancer. 2003;3(10): $721-32$. 
14. Samardzija C, Luwor R, Volchek M, Quinn M, Findlay J and Ahmed N. A critical role of Oct4A in mediating metastasis and disease-free survival in a mouse model of ovarian cancer. Molecular Cancer. 2015;14:152.

15. Schönenberger $D$, Rajski M, Harlander S, Frew IJ. Vhl deletion in renal epithelia causes HIF-1a-dependent, HIF-2a-independent angiogenesis and constitutive diuresis. Oncotarget. 2016;7(38):60971-85.

16. Meléndez-Rodríguez F, Roche O, Sanchez-Prieto R, Aragones J. Hypoxiainducible factor 2-dependent pathways driving Von Hippel-Lindau-deficient renal Cancer. Front Oncol. 2018;8:214.

17. Shen C, Kaelin WG Jr. The VHL/HIF axis in clear cell renal carcinoma. Semin Cancer Biol. 2013;23(1):18-25.

18. Gordan JD, Thompson CB, Simon MC. HIF and C-Myc: sibling rivals for control of cancer cell metabolism and proliferation. Cancer Cell. 2007;12(2): 108-13.

19. Gerlinger M, Horswell S, Larkin J, Rowan AJ, Salm MP, Varela I, et al. Genomic architecture and evolution of clear cell renal cell carcinomas defined by multiregion sequencing. Nat Genet. 2014;46(3):225-33.

20. Bihr S, Ohashi R, Moore AL, Rüschoff JH, Beisel C, Hermanns T, et al. Expression and mutation patterns of PBRM1, BAP1 and SETD2 Mirror specific evolutionary subtypes in clear cell renal cell carcinoma. Neoplasia. 2019:21(2):247-56.

21. McCarty G, Awad O, Loeb DM. WT1 protein directly regulates expression of vascular endothelial growth factor and is a mediator of tumor response to hypoxia. J Biol Chem. 2011;286(51):43634-43.

22. Que WC, Qiu HQ, Cheng Y, Liu MB, Wu CY. PTEN in kidney cancer: a review and meta-analysis. Clin Chim Acta. 2018;480:92-8.

23. Girgin C, Tarhan H, Hekimgil M, Sezer A, Gürel G. p53 mutations and other prognostic factors of renal cell carcinoma. Urol Int. 2001;66(2):78-83.

24. Razafinjatovo CF, Stiehl D, Deininger E, Rechsteiner M, Moch H, Schraml P. VHL missense mutations in the p53 binding domain show different effects on p53 signaling and HIFa degradation in clear cell renal cell carcinoma. Oncotarget. 2017:8(6):10199-212.

25. He H, Magi-Galluzzi C. Epithelial-to-mesenchymal transition in renal neoplasms. Adv Anat Pathol. 2014;21(3):174-80.

26. Fang Y, Wei J, Cao J, Zhao H, Liao B, Qiu S, et al. Protein expression of ZEB2 in renal cell carcinoma and its prognostic significance in patient survival. PLoS One. 2013;8(5):e62558.

27. Mikami S, Katsube K, Oya M, Ishida M, Kosaka T, Mizuno R, et al. Expression of snail and slug in renal cell carcinoma: E-cadherin repressor snail is associated with cancer invasion and prognosis. Lab Investig. 2011;91(10):1443-58.

28. Weygant N, Qu D, May R, Tierney RM, Berry WL, Zhao L, et al. DCLK1 is a broadly dysregulated target against epithelial-mesenchymal transition, focal adhesion, and stemness in clear cell renal carcinoma. Oncotarget. 2015;6(4): 2193-205.

29. The Cancer Genome Atlas Research Network, Analysis working group: Baylor College of Medicine, Creighton C, et al. Comprehensive molecular characterization of clear cell renal cell carcinoma. Nature. 2013:499:43-9.

30. Dumanskiy W, Kudriashov AG, Vasilenko IV, Kondratyuk RB, Gulkov YK, Cyrillichystiakov RS. Markers of epithelial-mesenchymal transition in renal cell carcinoma. Exp Oncol. 2013;35(4):325-7.

31. Harada K, Miyake H, Kusuda Y, Fujisawa M. Expression of epithelialmesenchymal transition markers in renal cell carcinoma: impact on prognostic outcomes in patients undergoing radical nephrectomy. BJU Int 2012;110(11 Pt C):E1131-7.

32. Conant JL, Peng Z, Evans MF, Naud S, Cooper K. Sarcomatoid renal cell carcinoma is an example of epithelial--mesenchymal transition. J Clin Pathol. 2011;64(12):1088-92.

33. Boström AK, Möller C, Nilsson E, Elfving P, Axelson H, Johansson ME. Sarcomatoid conversion of clear cell renal cell carcinoma in relation to epithelial-to-mesenchymal transition. Hum Pathol. 2012;43(5):70819.

34. Landolt L, Eikrem $\varnothing$, Strauss $P$, Scherer A, Lovett DH, Beisland C, et al. Clear cell renal cell carcinoma is linked to epithelial-to-Mesenchymal transition and to fibrosis. Phys Rep. 2017:5(11):e13305.

35. Chen Q, Yang D, Zong H, Zhu L, Wang L, Wang X, et al. Growth-induced stress enhances epithelial-mesenchymal transition induced by IL-6 in clear cell renal cell carcinoma via the Akt/GSK-3 $\beta / \beta$-catenin signaling pathway. Oncogenesis. 2017;6(8):e375-e.

36. Zhou N, Lu F, Liu C, Xu K, Huang J, Yu D, et al. IL-8 induces the epithelialmesenchymal transition of renal cell carcinoma cells through the activation of AKT signaling. Oncol Lett. 2016;12(3):1915-20.
37. Khawam K, Giron-Michel J, Gu Y, Perier A, Giuliani M, Caignard A, et al. Human renal cancer cells express a novel membrane-bound interleukin-15 that induces, in response to the soluble interleukin-15 receptor alpha chain, epithelial-to-mesenchymal transition. Cancer Res. 2009;69(4):1561-9.

38. Ho M-Y, Tang S-J, Chuang M-J, Cha T-L, Li J-Y, Sun G-H, et al. TNF-a induces epithelial-Mesenchymal transition of renal cell carcinoma cells via a GSK3ßdependent mechanism. Mol Cancer Res. 2012;10(8):1109-19.

39. Mahalingaiah PKS, Ponnusamy L, Singh KP. Chronic oxidative stress leads to malignant transformation along with Acquisition of Stem Cell Characteristics, and epithelial to Mesenchymal transition in human renal epithelial cells. J Cell Physiol. 2015;230(8):1916-28.

40. Yoshino H, Enokida H, Itesako T, Tatarano S, Kinoshita T, Fuse M, et al. Epithelial-mesenchymal transition-related microRNA-200s regulate molecular targets and pathways in renal cell carcinoma. J Hum Genet. 2013; 58(8):508-16.

41. Singla M, Kumar A, Bal A, Sarkar S, Bhattacharyya S. Epithelial to mesenchymal transition induces stem cell like phenotype in renal cell carcinoma cells. Cancer Cell Int. 2018;18:57.

42. Mimeault M, Batra SK. Targeting of cancer stem/progenitor cells plus stem cell-based therapies: the ultimate hope for treating and curing aggressive and recurrent cancers. Panminerva Med. 2008:50(1):3-18.

43. Marusyk A, Polyak K. Tumor heterogeneity: causes and consequences. Biochim Biophys Acta Rev Cancer. 2010;1805(1):105-17.

44. Myszczyszyn A, Czarnecka AM, Matak D, Szymanski L, Lian F, Kornakiewicz A, et al. The role of hypoxia and Cancer stem cells in renal cell carcinoma pathogenesis. Stem Cell Rev Rep. 2015;11(6):919-43.

45. Magee JA, Piskounova E, Morrison SJ. Cancer stem cells: impact, heterogeneity, and uncertainty. Cancer Cell. 2012;21(3):283-96.

46. Meacham CE, Morrison SJ. Tumour heterogeneity and cancer cell plasticity. Nature. 2013;501(7467):328-37.

47. Sell S. Stem cell origin of cancer and differentiation therapy. Crit Rev Oncol Hematol. 2004:51(1):1-28.

48. Mani SA, Guo W, Liao MJ, Eaton EN, Ayyanan A, Zhou AY, et al. The epithelial-mesenchymal transition generates cells with properties of stem cells. Cell. 2008;133(4):704-15.

49. Morel AP, Lièvre M, Thomas C, Hinkal G, Ansieau S, Puisieux A. Generation of breast cancer stem cells through epithelial-mesenchymal transition. PLoS One. 2008:3(8):e2888.

50. Dumont N, Wilson MB, Crawford YG, Reynolds PA, Sigaroudinia M, Tlsty TD. Sustained induction of epithelial to mesenchymal transition activates DNA methylation of genes silenced in basal-like breast cancers. Proc Natl Acad Sci U S A. 2008;105(39):14867-72.

51. Kurrey NK, Jalgaonkar SP, Joglekar AV, Ghanate AD, Chaskar PD, Doiphode $R Y$, et al. Snail and slug mediate radioresistance and chemoresistance by antagonizing p53-mediated apoptosis and acquiring a stem-like phenotype in ovarian cancer cells. Stem Cells. 2009;27(9):2059-68.

52. Addla SK, Brown MD, Hart CA, Ramani VAC, Clarke NW. Characterization of the Hoechst 33342 side population from normal and malignant human renal epithelial cells. Am J Physiol Ren Physiol. 2008;295(3):F680-F7.

53. Yuan Z-x, Mo J, Zhao G, Shu G, Fu H-I, Zhao W. Targeting strategies for renal cell carcinoma: from renal Cancer cells to renal Cancer stem cells. Front Pharmacol. 2016;7:423.

54. Hill RP, Marie-Egyptienne DT, Hedley DW. Cancer stem cells, hypoxia and metastasis. Semin Radiat Oncol. 2009;19(2):106-11.

55. Krishnamachary B, Zagzag D, Nagasawa H, Rainey K, Okuyama H, Baek JH, et al. Hypoxia-inducible Factor-1-dependent repression of $<e m>E$ cadherin</em> in von Hippel-Lindau tumor suppressor-null renal cell carcinoma mediated by TCF3, ZFHX1A, and ZFHX1B. Cancer Res. 2006;66(5): 2725-31.

56. Yang Z, Xie H, He D, Li L. Infiltrating macrophages increase RCC epithelial mesenchymal transition (EMT) and stem cell-like populations via AKT and mTOR signaling. Oncotarget. 2016;7(28):44478-91.

57. Zhou L, Liu XD, Sun M, Zhang X, German P, Bai S, et al. Targeting MET and $\mathrm{AXL}$ overcomes resistance to sunitinib therapy in renal cell carcinoma. Oncogene. 2016;35(21):2687-97.

58. Finke JH, Rayman PA, Ko JS, Bradley JM, Gendler SJ, Cohen PA. Modification of the tumor microenvironment as a novel target of renal cell carcinoma therapeutics. Cancer J. 2013:19(4):353-64.

59. Jing $X$, Yang F, Shao C, Wei $K$, Xie M, Shen $H$, et al. Role of hypoxia in cancer therapy by regulating the tumor microenvironment. Mol Cancer 2019;18(1):157. 
60. Ahmed N, Escalona R, Leung D, Chan E, Kannourakis G. Tumour microenvironment and metabolic plasticity in cancer and cancer stem cells: perspectives on metabolic and immune regulatory signatures in chemoresistant ovarian cancer stem cells. Semin Cancer Biol. 2018:53:265-81.

61. van der Veldt AA, Vroling L, de Haas RR, Koolwijk P, van den Eertwegh AJ, Haanen JB, et al. Sunitinib-induced changes in circulating endothelial cellrelated proteins in patients with metastatic renal cell cancer. Int J Cancer. 2012;131(4):E484-93.

62. Akino T, Hida K, Hida Y, Tsuchiya K, Freedman D, Muraki C, et al. Cytogenetic abnormalities of tumor-associated endothelial cells in human malignant tumors. Am J Pathol. 2009;175(6):2657-67.

63. Hida K, Hida Y, Amin DN, et al. Tumor-associated endothelial cells with cytogenetic abnormalities. Cancer Res. 2004;64(22):8249-55.

64. Kondoh M, Ohga N, Akiyama K, Hida Y, Maishi N, et al. Hypoxia-induced reactive oxygen species cause chromosomal abnormalities in endothelial cells in the tumor microenvironment. PLOSONE. 2013;8(11):e80349.

65. Ohga N, Ishikawa S, Maishi N, et al. Heterogeneity of tumor endothelial cells: comparison between tumor endothelial cells isolated from high- and low-metastatic tumors. Am J Pathol. 2012;180(3):1294-307.

66. Bussolati B, Grange C, Camussi G. Tumor exploits alternative strategies to achieve vascularization. FASEB J. 2011;25:2874-82.

67. Grange C, Bussolati B, Bruno S, Fonsato V, Sapino A, Camussi G. Isolation and characterization of human breast tumor-derived endothelial cells. Oncol Rep. 2006;15(2):381-6.

68. Virrey JJ, Golden EB, Sivakumar W, et al. Glioma-associated endothelial cells are chemoresistant to temozolomide. J Neuro-Oncol. 2009;95(1):13-22.

69. Xiong $Y Q$, Sun $\mathrm{HC}$, Zhang $W$, et al. Human hepatocellular carcinoma tumorderived endothelial cells manifest increased angiogenesis capability and drug resistance compared with normal endothelial cells. Clin Cancer Res. 2009;15(15):4838-46.

70. Fonsato V, Buttiglieri S, Deregibus MC, Bussolati B, Caselli E, Di Luca D, et al. PAX2 expression by HHV-8-infected endothelial cells induced a proangiogenic and proinvasive phenotype. Blood. 2008;111(5):2806-15.

71. Bussolati B, Deambrosis I, Russo S, Deregibus MC, Camussi G. Altered angiogenesis and survival in human tumor-derived endothelial cells. FASEB J. 2003:17:1159-61.

72. Bussolati B, Assenzio B, Deregibus MC, Camussi G. The proangiogenic phenotype of human tumor-derived endothelial cells depends on thrombospondin-1 downregulation via phosphatidylinositol 3-kinase/Akt pathway. J Mol Med (Berl). 2006:84(10):852-63.

73. Muraki C, Ohga N, Hida Y, et al. Cyclooxygenase-2 inhibition causes antiangiogenic effects on tumor endothelial and vascular progenitor cells. Int J Cancer. 2012;130(1):59-70.

74. Mangieri D, Nico B, Benagiano V, De Giorgis M, Vacca A, Ribatti D. Angiogenic activity of multiple myeloma endothelial cells in vivo in the chick embryo chorioallantoic membrane assay is associated to a downregulation in the expression of endogenous endostatin. J Cell Mol Med. 2008;12(3):1023-8.

75. Bussolati B, Grange C, Sapino A, Camussi G. Endothelial cell differentiation of human breast tumour stem/progenitor cells. J Cell Mol Med. 2009;13(2):309-19.

76. Alvero $A B, C$ hen $\mathrm{R}$, Fu HH, et al. Molecular phenotyping of human ovarian cancer stem cells unravels the mechanisms for repair and chemoresistance. Cell Cycle. 2009;8(1):158-66.

77. Bussolati B, Bruno S, Grange C, Ferrando U, Camussi G. Identification of a tumor-initiating stem cell population in human renal carcinomas. FASEB J. 2008;22(10):3696-705.

78. Bruno S, Bussolati B, Grange C, et al. CD133+ renal progenitor cells contribute to tumor angiogenesis. Am J Pathol. 2006;169(6):2223-35.

79. Das B, Tsuchida R, Malkin D, Koren G, Baruchel S, Yeger H. Hypoxia enhances tumor stemness by increasing the invasive and tumorigenic side population fraction. Stem Cells. 2008;26(7):1818-30

80. Jögi A, Øra I, Nilsson H, et al. Hypoxia alters gene expression in human neuroblastoma cells toward an immature and neural crest-like phenotype. Proc Natl Acad Sci U S A. 2002:99(10):7021-6.

81. Pietras A, Hansford LM, Johnsson AS, et al. HIF-2alpha maintains an undifferentiated state in neural crest-like human neuroblastoma tumorinitiating cells. Proc Natl Acad Sci U S A. 2009;106(39):16805-10.

82. Li Z, Bao S, Wu Q, et al. Hypoxia-inducible factors regulate tumorigenic capacity of glioma stem cells. Cancer Cell. 2009;15(6):501-13.
83. Soeda A, Park M, Lee D, et al. Hypoxia promotes expansion of the CD133positive glioma stem cells through activation of HIF-1alpha. Oncogene. 2009;28(45):3949-59.

84. Seidel S, Garvalov BK, Wirta $\vee$, et al. A hypoxic niche regulates glioblastoma stem cells through hypoxia inducible factor 2 alpha. Brain. 2010;133(Pt 4): 983-95.

85. Kakarla S, Song XT, Gottschalk S. Cancer-associated fibroblasts as targets for immunotherapy. Immunotherapy. 2012;4(11):1129-38.

86. Errarte $P$, Guarch R, Pulido R, et al. The expression of fibroblast activation protein in clear cell renal cell carcinomas is associated with synchronous lymph node metastases. PLoS One. 2016;11(12):e0169105.

87. Hakimi AA, Voss MH, Kuo F, et al. Transcriptomic profiling of the tumor microenvironment reveals distinct subgroups of clear cell renal cell Cancer: data from a randomized phase III trial. Cancer Discov. 2019;9(4):510-25.

88. Errarte P, Larrinaga G, López Jl. The role of cancer-associated fibroblasts in renal cell carcinoma. An example of tumor modulation through tumor/nontumor cell interactions. J Adv Res. 2020;21:103-8.

89. Tran TA, Leong HS, Pavia-Jimenez A, Fedyshyn S, Yang J, Kucejova B, et al. Fibroblast growth factor receptor-dependent and -independent paracrine signaling by Sunitinib-resistant renal cell carcinoma. Mol Cell Biol. 2016;36(13):1836-55.

90. Nagl L, Horvath L, Pircher A, Wolf D. Tumor endothelial cells (TECs) as potential immune directors of the tumor microenvironment - new findings and future perspectives. Front Cell Dev Biol. 2020;8:766.

91. Balch CM, Riley LB, Bae YJ, et al. Patterns of human tumor-infiltrating lymphocytes in 120 human cancers. Arch Surg. 1990;125(2):200-5.

92. MacFarlane AW 4th, Jillab M, Plimack ER, et al. PD-1 expression on peripheral blood cells increases with stage in renal cell carcinoma patients and is rapidly reduced after surgical tumor resection. Cancer Immunol Res. 2014;2(4):320-31.

93. Thompson $\mathrm{RH}$, Dong $\mathrm{H}$, Lohse $\mathrm{CM}$, et al. PD-1 is expressed by tumorinfiltrating immune cells and is associated with poor outcome for patients with renal cell carcinoma. Clin Cancer Res. 2007;13(6):1757-61.

94. Giraldo NA, Becht E, Vano Y, et al. Tumor-infiltrating and peripheral blood Tcell Immunophenotypes predict early relapse in localized clear cell renal cell carcinoma. Clin Cancer Res. 2017;23(15):4416-28.

95. Ficial M, Jegede O, Sant'Angelo M, Moreno S, Braun DA, Wind-Rotolo M, et al. Evaluation of predictive biomarkers for nivolumab in patients (pts) with metastatic clear cell renal cell carcinoma (mccRCC) from the CheckMate-025 (CM-025) trial. J Clin Oncol. 2020;38:5023.

96. Li S, Huang C, Hu G, Ma J, Chen Y, Zhang J, et al. Tumor-educated B cells promote renal cancer metastasis via inducing the IL-1 $/ / \mathrm{HIF-2} \alpha /$ Notch 1 signals. Cell Death Dis. 2020;11(3):163.

97. Somasundaram R, Zhang G, Fukunaga-Kalabis M, Perego M, Krepler C, Xu X, et al. Tumor-associated B-cells induce tumor heterogeneity and therapy resistance. Nat Commun. 2017;8(1):607.

98. Barth DA, Drula R, Ott L, et al. Circulating non-coding RNAs in renal cell carcinoma-pathogenesis and potential implications as clinical biomarkers. Front Cell Dev Biol. 2020;8:828

99. Zhao A, Li G, Péoc'h M, Genin C, Gigante M. Serum miR-210 as a novel biomarker for molecular diagnosis of clear cell renal cell carcinoma. Exp Mol Pathol. 2013:94(1):115-20.

100. Iwamoto H, Kanda Y, Sejima T, Osaki M, Okada F, Takenaka A. Serum miR210 as a potential biomarker of early clear cell renal cell carcinoma. Int J Oncol. 2014;44(1):53-8

101. Liu TY, Zhang H, Du SM, Li J, Wen XH. Expression of microRNA-210 in tissue and serum of renal carcinoma patients and its effect on renal carcinoma cell proliferation, apoptosis, and invasion. Genet Mol Res. 2016;15(1): 15017746.

102. Dias F, Teixeira AL, Ferreira M, et al. Plasmatic miR-210, miR-221 and miR1233 profile: potential liquid biopsies candidates for renal cell carcinoma. Oncotarget. 2017;8(61):103315-26.

103. Dang K, Myers KA. The role of hypoxia-induced miR-210 in cancer progression. Int J Mol Sci. 2015;16(3):6353-72.

104. Wang C, Wu C, Yang Q, et al. miR-28-5p acts as a tumor suppressor in renal cell carcinoma for multiple antitumor effects by targeting RAP1B. Oncotarget. 2016;7(45):73888-902.

105. Redova M, Poprach A, Nekvindova J, et al. Circulating miR-378 and miR-451 in serum are potential biomarkers for renal cell carcinoma. J Transl Med. 2012;10:55. 
106. Motzer RJ, Mazumdar M, Bacik J, Berg W, Amsterdam A, Ferrara J. Survival and prognostic stratification of 670 patients with advanced renal cell carcinoma. J Clin Oncol. 1999;17(8):2530.

107. Wirth M. The current use of Interferons, Interleukin-2 and tumor necrosis factor in renal cell Cancer. Urol Int. 1991;47(4):219-30.

108. Brugarolas J. Molecular genetics of clear-cell renal cell carcinoma. J Clin Oncol. 2014;32(18):1968-76.

109. AVEGF-TKIns MB, Tannir NM. Current and emerging therapies for first-line treatment of metastatic clear cell renal cell carcinoma. Cancer Treat Rev. 2018;70:127-37.

110. Rini BI, Halabi S, Rosenberg JE, Stadler WM, Vaena DA, Archer L, et al. Phase III trial of Bevacizumab plus interferon Alfa versus interferon Alfa Monotherapy in patients with metastatic renal cell carcinoma: final results of CALGB 90206. J Clin Oncol. 2010;28(13):2137-43.

111. Rini Bl, Plimack ER, Stus V, Gafanov R, Hawkins R, Nosov D, et al. Pembrolizumab (pembro) plus axitinib (axi) versus sunitinib as first-line therapy for metastatic renal cell carcinoma (mRCC): Outcomes in the combined IMDC intermediate/poor risk and sarcomatoid subgroups of the phase 3 KEYNOTE-426 study. J Clin Oncol. 2019;37(15_suppl):4500.

112. Motzer RJ, Rini BI, Bukowski RM, Curti BD, George DJ, Hudes GR, et al. Sunitinib in patients with metastatic renal cell carcinoma. JAMA. 2006; 295(21):2516-24

113. Faivre S, Delbaldo C, Vera K, Robert C, Lozahic S, Lassau N, et al. Safety, pharmacokinetic, and antitumor activity of SU11248, a novel Oral multitarget tyrosine kinase inhibitor, in patients with Cancer. J Clin Oncol. 2006;24(1):25-35.

114. Motzer RJ, Hutson TE, Tomczak P, Michaelson MD, Bukowski RM, Oudard S, et al. Overall survival and updated results for Sunitinib compared with interferon Alfa in patients with metastatic renal cell carcinoma. J Clin Oncol. 2009:27(22):3584-90

115. Sternberg CN, Davis ID, Mardiak J, Szczylik C, Lee E, Wagstaff J, et al. Pazopanib in locally advanced or metastatic renal cell carcinoma: results of a randomized phase III trial. J Clin Oncol. 2010;28(6):1061-8.

116. Sternberg CN, Hawkins RE, Wagstaff J, Salman P, Mardiak J, Barrios CH, et al. A randomised, double-blind phase III study of pazopanib in patients with advanced and/or metastatic renal cell carcinoma: final overall survival results and safety update. Eur J Cancer. 2013;49(6):1287-96.

117. Motzer RJ, Hutson TE, Cella D, Reeves J, Hawkins R, Guo J, et al. Pazopanib versus Sunitinib in Metastatic Renal-Cell Carcinoma. N Engl J Med. 2013; 369(8):722-31.

118. Escudier B, Porta C, Bono P, Powles T, Eisen T, Sternberg CN, et al. Randomized, controlled, double-blind, cross-over trial assessing treatment preference for Pazopanib versus Sunitinib in patients with metastatic renal cell carcinoma: PISCES study. J Clin Oncol. 2014;32(14):1412-8.

119. Bandyopadhyay S, Das P, Davies J, Puttarachaiah L, Seneviratne L, Lawrence C. Can we translate non-inferiority clinical trial into practice? Real world outcome of Sunitinib and Pazopanib as first line targeted therapy in metastatic renal cell carcinoma: UK Centre experience. Clin Oncol. 2020; 32(5):e131.

120. Lalani A-KA, Li H, Heng DYC, Wood L, Kalirai A, Bjarnason GA, et al. First-line sunitinib or pazopanib in metastatic renal cell carcinoma: the Canadian experience. Can Urol Assoc J. 2017;11(3-4):112-7.

121. Santoni M, Conti A, Porta C, Procopio G, Sternberg CN, Basso U, et al. Sunitinib, Pazopanib or Sorafenib for the treatment of patients with late relapsing metastatic renal cell carcinoma. J Urol. 2015;193(1):41-7.

122. Ahmad T, Eisen T. Kinase inhibition with BAY 43-9006 in renal cell carcinoma. Clin Cancer Res. 2004;10(18):6388S-92S.

123. Wilhelm SM, Carter C, Tang L, Wilkie D, McNabola A, Rong $H$, et al. BAY 43-9006 exhibits broad Spectrum Oral antitumor activity and targets the RAF/MEK/ERK pathway and receptor tyrosine kinases involved in tumor progression and angiogenesis. Cancer Res. 2004 64(19):7099-109.

124. Escudier B, Szczylik C, Hutson TE, Demkow T, Staehler M, Rolland F, et al. Randomized phase II trial of first-line treatment with Sorafenib versus interferon Alfa-2a in patients with metastatic renal cell carcinoma. J Clin Oncol. 2009;27(8):1280-9.

125. Escudier B, Eisen T, Stadler WM, Szczylik C, Oudard S, Staehler M, et al. Sorafenib for treatment of renal cell carcinoma: final efficacy and safety results of the phase III treatment approaches in renal Cancer global evaluation trial. J Clin Oncol. 2009:27(20):3312-8.
126. National Comprehensive Cancer Network. NCCN Clinical Practice Guidelines in Oncology. Kidney Cancer.V.4.2018. Retrieved from https://jnccn360.org/ kidney/news/2018-updates-for-nccn-guidelines-for-kidney-cancer/.

127. Calvo E, Porta C, Grünwald V, Escudier B. The current and evolving landscape of first-line treatments for advanced renal cell carcinoma. Oncologist. 2019;24(3):338-48.

128. Retz M, Bedke J, Bögemann M, Grimm M-O, Zimmermann U, Müller L, et al. SWITCH II: phase III randomized, sequential, open-label study to evaluate the efficacy and safety of sorafenib-pazopanib versus pazopanib-sorafenib in the treatment of advanced or metastatic renal cell carcinoma (AUO AN 33/11). Eur J Cancer. 2019;107:37-45.

129. Hutson TE, Lesovoy V, Al-Shukri S, Stus VP, Lipatov ON, Bair AH, et al. Axitinib versus sorafenib as first-line therapy in patients with metastatic renal-cell carcinoma: a randomised open-label phase 3 trial. Lancet Oncol. 2013;14(13):1287-94.

130. Zarrabi K, Fang C, Wu S. New treatment options for metastatic renal cell carcinoma with prior anti-angiogenesis therapy. J Hematol Oncol. 2017; 10(1):38.

131. Vitale MG, Cartenì G. Recent developments in second and third line therapy of metastatic renal cell carcinoma. Expert Rev Anticancer Ther. 2016;16(5): 469-71.

132. Gibney GT, Aziz SA, Camp RL, Conrad P, Schwartz BE, Chen CR, et al. C-met is a prognostic marker and potential therapeutic target in clear cell renal cell carcinoma. Ann Oncol. 2013;24(2):343-9.

133. Choueiri TK, Escudier B, Powles T, Mainwaring PN, Rini BI, Donskov F, et al. Cabozantinib versus Everolimus in advanced renal-cell carcinoma. N Engl Med. 2015;373(19):1814-23.

134. Choueiri TK, Escudier B, Powles T, Tannir NM, Mainwaring PN, Rini Bl, et al. Cabozantinib versus everolimus in advanced renal cell carcinoma (METEOR) final results from a randomised, open-label, phase 3 trial. Lancet Oncol. 2016;17(7):917-27

135. Choueiri TK, Halabi S, Sanford BL, Hahn O, Michaelson MD, Walsh MK, et al. Cabozantinib versus Sunitinib as initial targeted therapy for patients with metastatic renal cell carcinoma of poor or intermediate risk: the Alliance A031203 CABOSUN trial. J Clin Oncol. 2017;35(6):591-7.

136. Choueiri TK, Hessel C, Halabi S, Sanford B, Hahn O, Michaelson MD et al. Progression-free survival (PFS) by independent review and updated overall survival (OS) results from alliance a031203 trial (cabosun): cabozantinib versus sunitinib as initial targeted therapy for patients with metastatic renal cell carcinoma (MRCC). Ann Oncol. 2017;28:v605-v49.

137. Escudier B, Porta C, Schmidinger M, Rioux-Leclercq N, Bex A, Khoo V, et al. Renal cell carcinoma: ESMO clinical practice guidelines for diagnosis, treatment and follow-up. Ann Oncol. 2019;30(5):706-20.

138. Martínez Chanzá N, Xie W, Asim Bilen M, et al. Cabozantinib in advanced non-clear-cell renal cell carcinoma: a multicentre, retrospective, cohort study. Lancet Oncol. 2019;20(4):581-90.

139. Luyo M, Carril-Ajuria L, Schutz F, Castellano D, De Velasco G. Double Immune Checkpoint Blockade in Renal Cell Carcinoma. Kidney Cancer. 2019; 3:163-70

140. Yang JC, Hughes M, Kammula U, Royal R, Sherry RM, Topalian SL, et al. Ipilimumab (anti-CTLA4 antibody) causes regression of metastatic renal cell cancer associated with enteritis and hypophysitis. J Immunother. 2007;30(8):825-30.

141. Hammers HJ, Plimack ER, Infante JR, Rini BI, McDermott DF, Lewis LD, et al. Safety and efficacy of Nivolumab in combination with Ipilimumab in metastatic renal cell carcinoma: the CheckMate 016 study. J Clin Oncol. 2017;35(34):3851-8.

142. Motzer RJ, Tannir NM, McDermott DF, Arén Frontera O, Melichar B, Choueiri TK, et al. Nivolumab plus Ipilimumab versus Sunitinib in advanced renal-cell carcinoma. N Engl J Med. 2018;378(14):1277-90.

143. Cella D, Grünwald V, Escudier B, Hammers HJ, George S, Nathan P, et al. Patient-reported outcomes of patients with advanced renal cell carcinoma treated with nivolumab plus ipilimumab versus sunitinib (CheckMate 214): a randomised, phase 3 trial. Lancet Oncol. 2019;20(2):297-310.

144. Hudes G, Carducci M, Tomczak P, Dutcher J, Figlin R, Kapoor A, et al. Temsirolimus, interferon Alfa, or both for advanced renal-cell carcinoma. N Engl J Med. 2007;356(22):2271-81.

145. Knox JJ, Barrios CH, Kim TM, Cosgriff T, Srimuninnimit V, Pittman K, et al. Final overall survival analysis for the phase II RECORD-3 study of first-line everolimus followed by sunitinib versus first-line sunitinib followed by everolimus in metastatic RCC. Ann Oncol. 2017:28(6):1339-45. 
146. Rini Bl, Plimack ER, Stus V, Gafanov R, Hawkins R, Nosov D, et al. Pembrolizumab plus Axitinib versus Sunitinib for advanced renal-cell carcinoma. N Engl J Med. 2019;380(12):1116-27.

147. Motzer RJ, Penkov K, Haanen J, Rini B, Albiges L, Campbell MT, et al. Avelumab plus Axitinib versus Sunitinib for advanced renal-cell carcinoma. N Engl J Med. 2019;380(12):1103-15.

148. Rodriguez-Vida A, Hutson TE, Bellmunt J, Strijbos MH. New treatment options for metastatic renal cell carcinoma. ESMO Open. 2017;2(2):e000185.

149. Motzer RJ, Hutson TE, Glen H, Michaelson MD, Molina A, Eisen T, et al. Lenvatinib, everolimus, and the combination in patients with metastatic renal cell carcinoma: a randomised, phase 2, open-label, multicentre trial. Lancet Oncol. 2015;16(15):1473-82.

150. Motzer RJ, Hutson TE, Ren M, Dutcus C, Larkin J. Independent assessment of lenvatinib plus everolimus in patients with metastatic renal cell carcinoma. Lancet Oncol. 2016:17(1):e4-5.

151. Muz B, de la Puente P, Azab F, Azab AK. The role of hypoxia in cancer progression, angiogenesis, metastasis, and resistance to therapy. Hypoxia (Auckl). 2015;3:83-92.

152. Vetizou M, Pitt JM, Daillere R, Lepage P, Waldschmitt N, Flament C, et al. Anticancer immunotherapy by CTLA-4 blockade relies on the gut microbiota. Science. 2015:350(6264):1079-84

153. Bergers $G$, Hanahan D. Modes of resistance to anti-angiogenic therapy. Nat Rev Cancer. 2008:8(8):592-603.

154. Rezapourbehnagh S, Yaşar H, Arslan Ç, Urun Y. Targeted agents and resistance mechanism in renal cell Cancer. Bull Urooncology. 2019;18:73-9.

155. Tsimafeyeu I, Demidov L, Stepanova E, Wynn N, Ta H. Overexpression of fibroblast growth factor receptors FGFR1 and FGFR2 in renal cell carcinoma. Scand J Urol Nephrol. 2011:45(3):190-5.

156. Wang X, Bullock AJ, Zhang L, Wei L, Yu D, Mahagaokar K, et al. The role of angiopoietins as potential therapeutic targets in renal cell carcinoma. Transl Oncol. 2014;7(2):188-95.

157. Huang H, Lai JY, Do J, Liu D, Li L, Del Rosario J, et al. Specifically targeting angiopoietin-2 inhibits angiogenesis, Tie2-expressing monocyte infiltration, and tumor growth. Clin Cancer Res. 2011;17(5):1001-11.

158. Ishibashi K, Koguchi T, Matsuoka K, Onagi A, Tanji R, Takinami-Honda R, et al. Interleukin-6 induces drug resistance in renal cell carcinoma. Fukushima J Med Sci. 2018;64(3):103-10.

159. Martin D, Galisteo R, GuVEGF-TKInd JS. CXCL8/IL8 stimulates vascular endothelial growth factor (VEGF) expression and the Autocrine activation of VEGFR2 in endothelial cells by activating NFKB through the CBM (Carma3/Bcl10/Malt1) complex. J Biol Chem. 2009;284(10): $6038-42$.

160. Huang D, Ding Y, Zhou M, Rini BI, Petillo D, Qian CN, et al. Interleukin-8 mediates resistance to antiangiogenic agent sunitinib in renal cell carcinoma. Cancer Res. 2010;70(3):1063-71.

161. Fischer C, Jonckx B, Mazzone M, Zacchigna S, Loges S, Pattarini L, et al. AntiPIGF inhibits growth of VEGF(R)-inhibitor-resistant tumors without affecting healthy vessels. Cell. 2007;131(3):463-75.

162. Chen J, Ding Z, Peng Y, Pan F, Li J, Zou L, et al. HIF-1a inhibition reverses multidrug resistance in colon cancer cells via downregulation of MDR1/Pglycoprotein. PLoS One. 2014;9(6):e98882.

163. Kumar V, Gabrilovich DI. Hypoxia-inducible factors in regulation of immune responses in tumour microenvironment. Immunology. 2014;143(4):512-9.

164. Noman MZ, Chouaib S. Targeting hypoxia at the forefront of anticancer immune responses. Oncoimmunology. 2015;3(12):e954463.

165. Barsoum IB, Koti M, Siemens DR, Graham CH. Mechanisms of hypoxiamediated immune escape in Cancer. Cancer Res. 2014:74(24):7185-90.

166. Gordan JD, Lal P, Dondeti VR, Letrero R, Parekh KN, Oquendo CE, et al. HIFalpha effects on C-Myc distinguish two subtypes of sporadic VHL-deficient clear cell renal carcinoma. Cancer Cell. 2008:14(6):435-46.

167. Gobé G, Rubin M, Williams G, Sawczuk I, Buttyan R. Apoptosis and expression of $\mathrm{BCl}-2, \mathrm{BCl}-\mathrm{XL}$, and $\mathrm{Bax}$ in renal cell carcinomas. Cancer Investig. 2002;20(3):324-32

168. Adelaiye-Ogala R, Budka J, Damayanti NP, Arrington J, Ferris M, Hsu C-C, et al. EZH2 modifies Sunitinib resistance in renal cell carcinoma by Kinome reprogramming. Cancer Res. 2017;77(23):6651-66.

169. Gotink KJ, Broxterman HJ, Labots M, de Haas RR, Dekker H, Honeywell RJ, et al. Lysosomal sequestration of sunitinib: a novel mechanism of drug resistance. Clin Cancer Res. 2011;17(23):7337-46.

170. Azijli K, Gotink KJ, Verheul HMW. The Potential Role of Lysosomal Sequestration in Sunitinib Resistance of Renal Cell Cancer. J Kidney Cancer
VHL. 2015;2(4):195-203 Available from http://europepmc.org/abstract/ MED/28326274; https://europepmc.org/articles/PMC5345522.

171. Wu S, Huang L, Shen R, Bernard-Cacciarella M, Zhou P, Hu C, et al. Drug resistance-related sunitinib sequestration in autophagolysosomes of endothelial cells. Int J Oncol. 2020;56(1):113-22.

172. Hossam Kamli LL, Glenda C. Gobe. Limitations to the therapeutic potential of tyrosine kinase inhibitors and alternative therapies for kidney Cancer. Ochsner J. 2019;19:138-51.

173. Cao Z, Shang B, Zhang G, Miele L, Sarkar FH, Wang Z, et al. Tumor cellmediated neovascularization and lymphangiogenesis contrive tumor progression and cancer metastasis. Biochim Biophys Acta. 2013;1836(2): 273-86.

174. Geevarghese A, Herman IM. Pericyte-endothelial crosstalk: implications and opportunities for advanced cellular therapies. Transl Res. 2014;163(4):296-306.

175. Hall AP. Review of the pericyte during angiogenesis and its role in cancer and diabetic retinopathy. Toxicol Pathol. 2006;34(6):763-75.

176. Bunt SK, Sinha P, Clements VK, Leips J, Ostrand-Rosenberg S. Inflammation induces myeloid-derived suppressor cells that facilitate tumor progression. $J$ Immunol. 2006:176(1):284-90.

177. Pollard JW. Tumour-educated macrophages promote tumour progression and metastasis. Nat Rev Cancer. 2004:4(1):71-8.

178. Hattori K, Heissig B, Wu Y, Dias S, Tejada R, Ferris B, et al. Placental growth factor reconstitutes hematopoiesis by recruiting VEGFR1(+) stem cells from bone-marrow microenvironment. Nat Med. 2002;8(8):841-9.

179. Poletto V, Rosti V, Biggiogera M, Guerra G, Moccia F, Porta C. The role of endothelial colony forming cells in kidney cancer's pathogenesis, and in resistance to anti-VEGFR agents and mTOR inhibitors: a speculative review. Crit Rev Oncol Hematol. 2018;132:89-99.

180. Lee NH. Pharmacogenetics of drug metabolizing enzymes and transporters: effects on pharmacokinetics and pharmacodynamics of anticancer agents. Anti Cancer Agents Med Chem. 2010;10(8):583-92.

181. Diekstra MHM, Swen JJ, Gelderblom H, Guchelaar H-J. A decade of pharmacogenomics research on tyrosine kinase inhibitors in metastatic renal cell cancer: a systematic review. Expert Rev Mol Diagn. 2016;16(5):605-18.

182. Diekstra MHM, Swen JJ, Boven E, Castellano D, Gelderblom H, Mathijssen $\mathrm{RHJ}$, et al. CYP3A5 and $A B C B 1$ polymorphisms as predictors for Sunitinib outcome in metastatic renal cell carcinoma. Eur Urol. 2015;68(4):621-9.

183. Beuselinck B, Karadimou A, Lambrechts D, Claes B, Wolter P, Couchy G, et al. Single-nucleotide polymorphisms associated with outcome in metastatic renal cell carcinoma treated with sunitinib. Br J Cancer. 2013;108(4):887-900.

184. Lu L, Li Y, Wen H, Feng C. Overexpression of miR-15b promotes resistance to Sunitinib in renal cell carcinoma. J Cancer. 2019;10(15):3389-96.

185. Yamaguchi N, Osaki M, Onuma K, Yumioka T, Iwamoto H, Sejima T, et al. Identification of MicroRNAs involved in resistance to Sunitinib in renal cell carcinoma cells. Anticancer Res. 2017;37(6):2985-92.

186. Brenner W, Farber G, Herget T, Lehr HA, Hengstler JG, Thuroff JW. Loss of tumor suppressor protein PTEN during renal carcinogenesis. Int J Cancer. 2002;99(1):53-7

187. Gubin MM, Zhang X, Schuster H, Caron E, Ward JP, Noguchi T, et al. Checkpoint blockade cancer immunotherapy targets tumour-specific mutant antigens. Nature. 2014;515(7528):577-81.

188. de Velasco G, Miao D, Voss MH, Hakimi AA, Hsieh JJ, Tannir NM, et al. Tumor mutational load and immune parameters across metastatic renal cell carcinoma risk groups. Cancer Immunol Res. 2016;4(10):820-2.

189. Steinman RM, Hawiger D, Nussenzweig MC. Tolerogenic dendritic cells. Annu Rev Immunol. 2003;21:685-711.

190. Veglia F, Gabrilovich DI. Dendritic cells in cancer: the role revisited. Curr Opin Immunol. 2017;45:43-51.

191. Gide TN, Wilmott JS, Scolyer RA, Long GV. Primary and acquired resistance to immune checkpoint inhibitors in metastatic melanoma. Clin Cancer Res. 2018;24(6):1260-70.

192. Chevrier S, Levine JH, Zanotelli VRT, Silina K, Schulz D, Bacac M, et al. An Immune Atlas of Clear Cell Renal Cell Carcinoma. Cell. 2017;169(4):736-49. e18.

193. Strauss L, Bergmann C, Szczepanski M, Gooding W, Johnson JT, Whiteside TL. A unique subset of CD4/CD25/Foxp3 T cells secreting Interleukin-10 and transforming growth factor- $\beta 1$ mediates suppression in the tumor microenvironment Clin Cancer Res. 2007:13(15):4345.

194. Srivastava MK, Sinha P, Clements VK, Rodriguez P, Ostrand-Rosenberg S. Myeloid-derived suppressor cells inhibit T-cell activation by depleting cystine and cysteine. Cancer Res. 2010;70(1):68-77. 
195. Highfill SL, Cui Y, Giles AJ, Smith JP, Zhang H, Morse E, et al. Disruption of CXCR2-mediated MDSC tumor trafficking enhances anti-PD1 efficacy. Sci Transl Med. 2014;6(237):237ra67.

196. Taylor NA, Vick SC, Iglesia MD, Brickey WJ, Midkiff BR, McKinnon KP, et al. Treg depletion potentiates checkpoint inhibition in claudin-low breast cancer. J Clin Invest. 2017;127(9):3472-83.

197. Pardoll DM. The blockade of immune checkpoints in cancer immunotherapy. Nat Rev Cancer. 2012;12(4):252-64.

198. Holmgaard RB, Zamarin D, Li Y, Gasmi B, Munn DH, Allison JP, et al. Tumorexpressed IDO recruits and activates MDSCs in a Treg-dependent manner. Cell Rep. 2015;13(2):412-24.

199. Andrews LP, Marciscano AE, Drake CG, Vignali DA. LAG3 (CD223) as a cancer immunotherapy target. Immunol Rev. 2017;276(1):80-96.

200. Das M, Zhu C, Kuchroo VK. Tim-3 and its role in regulating anti-tumor immunity. Immunol Rev. 2017:276(1):97-111.

201. Mollica V. Resistance to Systemic Agents in Renal Cell Carcinoma Predict and Overcome Genomic Strategies Adopted by Tumor. Cancers. 2019;11(6):830

202. Hong M, Puaux AL, Huang C, Loumagne L, Tow C, Mackay C, et al. Chemotherapy induces intratumoral expression of chemokines in cutaneous melanoma, favoring T-cell infiltration and tumor control. Cancer Res. 2011; 71(22):6997-7009.

203. Zhu YJ, Zheng B, Wang HY, Chen L. New knowledge of the mechanisms of sorafenib resistance in liver cancer. Acta Pharmacol Sin. 2017:38(5):614-22.

204. Routy B, Le Chatelier E, Derosa L, Duong CPM, Alou MT, Daillère R, et al. Gut microbiome influences efficacy of PD-1-based immunotherapy against epithelial tumors. Science. 2018;359(6371):91-7.

205. Derosa L, Hellmann MD, Spaziano M, Halpenny D, Fidelle M, Rizvi H, et al. Negative association of antibiotics on clinical activity of immune checkpoint inhibitors in patients with advanced renal cell and non-small-cell lung cancer. Ann Oncol. 2018;29(6):1437-44.

206. Guo C, Manjili MH, Subjeck JR, Sarkar D, Fisher PB, Wang X-Y. Therapeutic cancer vaccines: past, present, and future. Adv Cancer Res. 2013;119:421-75.

207. Gan HK, Millward M, Hua Y, Qi C, Sai Y, Su W, et al. First-in-human phase I study of the selective MET inhibitor, Savolitinib, in patients with advanced solid tumors: safety, pharmacokinetics, and antitumor activity. Clin Cancer Res. 2019;25:4924-32.

208. Voss MH, Bhatt RS, Vogelzang NJ, Fishman M, Alter RS, Rini Bl, et al. A phase 2, randomized trial evaluating the combination of dalantercept plus axitinib in patients with advanced clear cell renal cell carcinoma. Cancer. 2019; 125(14):2400-8.

209. Hosier GW, Touma NJ. Response of renal cell carcinoma to ibrutinib, a bruton tyrosine kinase inhibitor, in a patient treated for chronic lymphocytic leukemia. Can Urol Assoc J. 2017;11(5):E237-E9.

210. Li H, Ding J, Lu M, Liu H, Miao Y, Li L, et al. CAIX-specific CAR-T cells and Sunitinib show synergistic effects against metastatic renal Cancer models. J Immunother. 2020;43(1):16-28.

211. Kiweler N, Brill B, Wirth M, Breuksch I, Laguna T, Dietrich C, et al. The histone deacetylases HDAC1 and HDAC2 are required for the growth and survival of renal carcinoma cells. Arch Toxicol. 2018;92(7):2227-43.

212. Martins F, Sofiya L, Sykiotis GP, et al. Adverse effects of immune-checkpoint inhibitors: epidemiology, management and surveillance. Nat Rev Clin Oncol. 2019;16(9):563-80.

213. Solimando AG, Crudele L, Leone P, Argentiero A, Guarascio M, Silvestris N, et al. Immune checkpoint inhibitor-related myositis: from biology to bedside. Int J Mol Sci. 2020;21(9):3054

214. Nishino M, Ramaiya NH, Hatabu H, Hodi FS. Monitoring immune-checkpoint blockade: response evaluation and biomarker development. Nat Rev Clin Oncol. 2017;14(11):655-68.

215. Khan KA, Kerbel RS. Improving immunotherapy outcomes with antiangiogenic treatments and vice versa. Nat Rev Clin Oncol. 2018;15(5):31024.

216. Feng RM, Zong YN, Cao SM, et al. Current cancer situation in China: good or bad news from the 2018 Global Cancer Statistics? Cancer Commun. 2019; 39:22.

217. Wilson WR, Hay MP. Targeting hypoxia in cancer therapy. Nat Rev Cancer. 2011;11(6):393-410

218. Palazon A, Tyrakis PA, Macias D, et al. An HIF-1aNEGF-A Axis in Cytotoxic T Cells Regulates Tumor Progression. Cancer Cell. 2017;32(5):669-683.e5.

219. Solimando AG, Summa SD, Vacca A, Ribatti D. Cancer-associated angiogenesis: the endothelial cell as a checkpoint for immunological patrolling. Cancers. 2020;12(11):3380
220. Huang Y, Goel S, Duda DG, Fukumura D, Jain RK. Vascular normalization as an emerging strategy to enhance cancer immunotherapy. Cancer Res. 2013; 73(10):2943-8

221. Huang Y, Yuan J, Righi E, et al. Vascular normalizing doses of antiangiogenic treatment reprogram the immunosuppressive tumor microenvironment and enhance immunotherapy. Proc Natl Acad Sci U S A. 2012;109(43):17561-6.

222. Samples J, Willis M, Klauber-Demore N. Targeting angiogenesis and the tumor microenvironment. Surg Oncol Clin N Am. 2013;22(4):629-39.

223. Lugano R, Ramachandran M, Dimberg A. Tumor angiogenesis: causes, consequences, challenges and opportunities. Cell Mol Life Sci. 2020;77(9): 1745-70.

224. Jain RK. Antiangiogenesis strategies revisited: from starving tumors to alleviating hypoxia. Cancer Cell. 2014;26(5):605-22.

225. Lorgis V, Maura G, Coppa G, et al. Relation between bevacizumab dose intensity and high-grade glioma survival: a retrospective study in two large cohorts. J Neuro-Oncol. 2012;107(2):351-8.

226. Tolaney SM, Boucher Y, Duda DG, et al. Role of vascular density and normalization in response to neoadjuvant bevacizumab and chemotherapy in breast cancer patients. Proc Natl Acad Sci U S A. 2015;112(46):14325-30.

227. Fukumura D, Kloepper J, Amoozgar Z, Duda DG, Jain RK. Enhancing cancer immunotherapy using antiangiogenics: opportunities and challenges. Nat Rev Clin Oncol. 2018;15(5):325-40.

228. Lee WS, Yang $\mathrm{H}$, Chon HJ, et al. Combination of anti-angiogenic therapy and immune checkpoint blockade normalizes vascular-immune crosstalk to potentiate cancer immunity. Exp Mol Med. 2020;52:1475-85.

229. Makker V, Rasco D, Vogelzang NJ, et al. Lenvatinib plus pembrolizumab in patients with advanced endometrial cancer: an interim analysis of a multicentre, open-label, single-arm, phase 2 trial. Lancet Oncol. 2019;20(5): $711-8$.

230. Miron B, Xu D, Zibelman M. Biomarker Development for Metastatic Renal Cell Carcinoma: Omics, Antigens, T-cells, and Beyond. J Pers Med. 2020; 10(4):225.

231. Argentiero A, Solimando AG, Krebs M, et al. Anti-angiogenesis and Immunotherapy: Novel Paradigms to Envision Tailored Approaches in Renal Cell-Carcinoma. J Clin Med. 2020;9(5):1594.

232. Li X, Song W, Shao C, Shi Y, Han W. Emerging predictors of the response to the blockade of immune checkpoints in cancer therapy. Cell Mol Immunol. 2019;16(1):28-39.

\section{Publisher's Note}

Springer Nature remains neutral with regard to jurisdictional claims in published maps and institutional affiliations.

Ready to submit your research? Choose BMC and benefit from:

- fast, convenient online submission

- thorough peer review by experienced researchers in your field

- rapid publication on acceptance

- support for research data, including large and complex data types

- gold Open Access which fosters wider collaboration and increased citations

- maximum visibility for your research: over $100 \mathrm{M}$ website views per year

At $\mathrm{BMC}$, research is always in progress.

Learn more biomedcentral.com/submission 